\title{
Comparative Pro-cognitive and Neurochemical Profiles of Glycine Modulatory Site Agonists and Glycine Reuptake Inhibitors in the Rat: Potential Relevance to Cognitive Dysfunction and Its Management
}

\author{
Kevin C.F. Fone ${ }^{1}$ (D) David J.G. Watson ${ }^{1} \cdot$ Rodolphe I. Billiras $^{2} \cdot$ Dorothee I. Sicard $^{2} \cdot$ Anne Dekeyne $^{2} \cdot$ \\ Jean-Michel Rivet ${ }^{2}$ - Alain Gobert ${ }^{2}$ - Mark J. Millan ${ }^{2}$
}

Received: 7 August 2019 / Accepted: 9 January 2020 / Published online: 20 January 2020

(C) The Author(s) 2020

\begin{abstract}
Frontocortical NMDA receptors are pivotal in regulating cognition and mood, are hypofunctional in schizophrenia, and may contribute to autistic spectrum disorders. Despite extensive interest in agents potentiating activity at the co-agonist glycine modulatory site, few comparative functional studies exist. This study systematically compared the actions of the glycine reuptake inhibitors, sarcosine (40-200 mg/kg) and ORG24598 (0.63-5 mg/kg), the agonists, glycine (40-800 mg/kg), and D-serine (10$160 \mathrm{mg} / \mathrm{kg}$ ) and the partial agonists, S18841 (2.5 mg/kg s.c.) and D-cycloserine (2.5-40 mg/kg) that all dose-dependently prevented scopolamine disruption of social recognition in adult rats. Over similar dose ranges, they also prevented a delayinduced impairment of novel object recognition (NOR). Glycine reuptake inhibitors specifically elevated glycine but not D-serine levels in rat prefrontal cortical (PFC) microdialysates, while glycine and D-serine markedly increased levels of glycine and Dserine, respectively. D-Cycloserine slightly elevated D-serine levels. Conversely, S18841 exerted no influence on glycine, Dserine, other amino acids, monamines, or acetylcholine. Reversal of NOR deficits by systemic S18841 was prevented by the NMDA receptor antagonist, CPP (20 mg/kg), and the glycine modulatory site antagonist, L701,324 (10 mg/kg). S18841 blocked deficits in NOR following microinjection into the PFC $(2.5-10 \mu \mathrm{g} / \mathrm{side})$ but not the striatum. Finally, in rats socially isolated from weaning (a neurodevelopmental model of schizophrenia), S18841 (2.5 and $10 \mathrm{mg} / \mathrm{kg}$ s.c.) reversed impairment of NOR and contextual fear-motivated learning without altering isolation-induced hyperactivity. In conclusion, despite contrasting neurochemical profiles, partial glycine site agonists and glycine reuptake inhibitors exhibit comparable pro-cognitive effects in rats of potential relevance to treatment of schizophrenia and other brain disorders where cognitive performance is impaired.
\end{abstract}

Keywords NMDA receptor - Glycine modulatory site - D-serine · Cognition · Social cognition · Prefrontal cortex · Schizophrenia $\cdot$ Microdialysis

Electronic supplementary material The online version of this article (https://doi.org/10.1007/s12035-020-01875-9) contains supplementary material, which is available to authorized users.

Kevin C.F. Fone

kevin.fone@nottingham.ac.uk

$\bowtie$ Mark J. Millan

mark.millan@servier.com

1 School of Life Sciences, Queen's Medical Centre, The University of Nottingham, Nottingham NG7 2UH, UK

2 Centre for Therapeutic Innovation-CNS, Institut de Recherche Servier, Centre de Recherches de Croissy, 125 Chemin de Ronde, 78290 Croissy-sur-Seine, France

\section{Introduction}

The role of glutamatergic dysfunction in psychiatric disorders is well established, and N-methyl-D-aspartate (NMDA) receptors retain special interest because of their broad cortical and subcortical distribution, localisation on GABAergic interneurons and pyramidal cells, and key role in regulation of neuroplasticity, cognition, epilepsy, mood and motor behaviour. Furthermore, the NMDA channel blocker, ketamine is attracting interest as a fast-acting antidepressant which is metabolised to $(2 \mathrm{~S}, 6 \mathrm{~S} ; 2 \mathrm{R}, 6 \mathrm{R})$-hydroxynorketamine that activates AMPA receptors [1] and causes mTOR- and BDNFdependent increased dendritic arborisation in dopaminergic neurons which may be beneficial to other mood disorders [2, 
3]. Furthermore, agents promoting NMDA activity are also of potential use to treat Alzheimer's disease, Parkinson's disease, autism spectrum disorders (ASDs), and schizophrenia [4, 5].

Glutamate activation of the NMDA receptor requires concurrent binding of glycine or, predominantly in the PFC, Dserine at the glycine modulatory site [6-8]. Thus, pharmacological modulation of the glycine site has been prioritised to restore hypofunction by direct agonism, inhibition of enzymes regulating serine metabolism or increasing synaptic glycine by inhibition of glycine transporters [9-12]. Although glycine and Dserine have been extensively characterised, it has proven very hard to generate small molecule, positive modulators of the glycine site. Recently, the partial agonists GLYX-13 (rapastinel) [13] and ((2S, 3R)-3-hydroxy-2-((R)-5-isobutyryl1-oxo-2,5-diazaspiro[3,4]octan-2-yl)butanamide) NYX-2925 [14] were shown to enhance hippocampal LTP and cognition in rodent paradigms. Although the cyclic imidazolinone, S18841 [15], was not developed clinically, this glycine site partial agonist is a very useful ligand for exploitation in parallel with the prototypical partial agonist D-cycloserine to identify the functional roles of the glycine modulatory site and ascertain underlying potentially beneficial therapeutic mechanisms. This approach was supported by the current findings that unlike other agents tested, S18841 did not significantly elevate microdialysate glycine levels making it a particularly informative agent to examine the impact of partial agonism at the glycine site on cognitive function.

NMDA receptor hypofunction is strongly implicated in the pathogenesis of schizophrenia [16, 17]. Moreover, increased levels of the endogenous NMDA receptor antagonists, Nacetylaspartylglutamate (NAAG), and kynurenate, occur in the cortex and hippocampus [18] along with decreased plasma D-serine [19] but see [20] and glycine in schizophrenia, and depletion of the latter correlates with severity of negative symptoms [21]. Genetic and functional studies suggest alterations in the rate-limiting enzyme for D-serine synthesis, D-serine racemase, and the major metabolising enzyme D-amino oxidase particularly in the prefrontal cortex (PFC) may contribute to NMDA receptor hypofunction in schizophrenia [16, 22]. DCycloserine and the tetrapeptide glycine partial agonist, GLIX13, improve social behaviour in mice models of ASD [23] and D-cycloserine alleviated anxiety, social and vocal communication changes in the valproate rat model of ASD [24] as well as attenuating stereotype behaviour in 20 young ASD patients [25], but there have been few other clinical trials.

Over 70 placebo-controlled clinical trials with glycine modulatory site compounds (including glycine, D-serine, Dcycloserine and sodium benzoate) often given as adjuncts to antipsychotics have shown inconsistent and at best modest improvement in negative symptoms or cognitive domains $[10,17,26]$. Such inconsistent findings could be due to a bell-shaped dose response effect; desensitisation with chronic administration of glycine agonists, or muscarinic actions of antipsychotics preventing any cognitive improvement (as discussed fully later); or variation in the pharmacological effect of glycine agonists, partial agonists and GlyT1 inhibitors used, a possibility investigated herein. In comparison, another recent meta-analysis showed that NMDA modulators (glycine and D-serine) were more effective than amisulpiride, risperidone and olanzepine at reducing negative symptoms in adolescents at clinical high risk for developing psychosis [27]. Therefore, such drugs may be of potential use for preventing the transition of ultra-high-risk subjects to full-blown psychosis and schizophrenia [28, 29]. They also warrant further investigation as a treatment for ASD, particularly if preclinical evidence could identify unique pharmacological mechanisms associated with any benefit.

GlyT1 inhibitors like sarcosine, ORG25935, and bitopertin (RG1678), increase NMDA receptor-dependent hippocampal LTP [30] and attenuate PCP-induced hyper-responsiveness to d-amphetamine in rodent models [30]. A few studies have also shown the impact of GlyT1 inhibitors on behaviour in animal models for psychiatric disorders. The GlyT1 inhibitor, ALX5407 , increased prepulse inhibition of acoustic startle (PPI) in DAB/2 mice with naturally low PPI [31], ASP2535 reversed a neonatal phencyclidine-induced impairment of NOR [32], and ORG25935 reversed the attention deficit seen in the 5-choice continuous performance task in a transcription factor specificity protein 4 hypomorphic mouse model for bipolar disorder and schizophrenia [33]. Further, bitopertin showed initial promise against negative symptoms in phase II trials [34]. Although phase II/III clinical studies were disappointing [35, 36], recent add-on trials of the D-amino acid oxidase inhibitor, sodium benzoate with the GlyT1 inhibitor, sarcosine, improved cognitive and global functioning in patients with schizophrenia [12], so clinical evaluation of drugs that reinforce NMDA receptor activity remains of interest. The current study was therefore performed to determine the key cortical neurotransmitters involved in the cognitive effects of agents that modify glycine function. This should, in turn, help identify reasons underlying the poor predictive translational value of animal models for clinical trials in schizophrenia and help identify potential new therapeutic targets to overcome cognitive and social dysfunction in schizophrenia and other CNS disorders such as ASD.

As discussed above, few studies have compared the utility of glycine site direct agonists, partial agonists, and GlyT1 inhibitors, in relevant rodent models to clarify the potential clinical utility of these mechanisms and novel agents to treat schizophrenia. Accordingly, we compared the glycine modulatory site agonists (glycine, D-serine, D-cycloserine and S18841) and GlyT1 inhibitors (sarcosine and ORG25935) on microdialysis levels of glycine and D-serine and other neurotransmitters thought to regulate cognition in the prefrontal cortex (PFC) of rats [37]. These compounds were also compared in three cognitive tasks: social recognition, novel object 
recognition (NOR) and an associative conditioned freezing response (CFR) task (selected for translational relevance to schizophrenia from consensus reviews [38, 39], and whose predictive validity will be considered in the discussion). In addition, we employed a microinjection procedure to examine the role of the PFC in the action of S18841.

Finally, we examined the effect of S18841 in a neurodevelopmental model, rearing rats in social isolation from weaning, that produces behavioural and neurochemical changes resembling schizophrenia $[40,41]$ including reduced PFC volume [42, 43] and hippocampal expression of genes involved in glutamate, GABA and dopamine neurotransmission [44]. This model is associated with an impairment in NOR [44-47], CFR [45, 46, 48] and social interaction [49], making it ideal for the current investigation.

\section{Materials and Methods}

\section{Animals}

Male Lister hooded rats (Charles River UK) were used for the novel object recognition (NOR) and isolation studies, while male Wistar rats (Charles River L'Arbresle, France) were used for the social recognition and microdialysis studies. All rats were housed in conventional open top cages with food and water available ad libitum under $12 \mathrm{~h}$ light/dark cycle (lights on $07.00 \mathrm{~h}$ ) and constant temperature $21 \pm 2{ }^{\circ} \mathrm{C}$ and humidity $55 \pm 10 \%$. All behavioural studies were performed between 08.00 and $16.00 \mathrm{~h}$, and following every test, the apparatus was thoroughly cleaned with $20 \% \mathrm{v} / \mathrm{v}$ ethanol and dried to remove odour cues. All studies were performed using a blind protocol, so that the observer was unaware of drug treatment. Experiments were conducted in accordance with the Animals (Scientific Procedures) Act, 1986 and ARRIVE guidelines with approval of University of Nottingham Local Ethical Committee (behaviour) or EU guidelines (microdialysis). All efforts were made to minimise animal suffering, and the number of animals used.

\section{Extracellular Amino Acids Levels by Microdialysis}

Male Wistar rats (225-300 g) supplied by Charles River (L'Arbresle, France) were housed in groups (3-4) with free access to food and water. Rats were anaesthetised under chloral hydrate $(400 \mathrm{mg} / \mathrm{kg}$, i.p.) and a guide cannula implanted above the PFC at coordinates: $\mathrm{AP}+2.2, \mathrm{~L} \pm 0.6$ and $\mathrm{DV}-0.2$. [50]. Five days later, a cuprophane CMA/11 probe $(4 \mathrm{~mm})$ was implanted and perfused at $1 \mu \mathrm{l} / \mathrm{min}$ with a Ringer solution ( $\mathrm{NaCl} 147.2 \mathrm{mM} ; \mathrm{KCl} 4 \mathrm{mM}$ and $\mathrm{CaCl}_{2} 2.3 \mathrm{mM}$ buffered with phosphate at $\mathrm{pH}, 7.3$ ) for $150 \mathrm{~min}$ to obtain stable baseline levels, and samples taken every $20 \mathrm{~min}$ thereafter for $3 \mathrm{~h}$. Amino acid levels were measured in $5 \mu$ l dialysate using fluorimetric detection (ex 420 nm; em: 490 nm, FP2020plus, Jasco, Bouguenais, France) after separation by linear gradient chromatography $(0 \% \mathrm{~B}$ to $40 \% \mathrm{~B}$ over $40 \mathrm{~min}$ where the mobile phase was ammonium acetate $(50 \mathrm{mM}, \mathrm{pH}=6.8)$ plus tetrahydrofurane $(3 \%)$, and $\mathrm{B}$ was ammonium acetate (50 mM, pH $=6.8)$ plus acetonitrile $(60 \%)$ ) using a reverse phase column (Kromasil C18, $250 \mathrm{~mm} \times 2.1 \mathrm{~mm}$, particle size, $5 \mu \mathrm{m}$, Cluzeau Info Labo, Courbevoie, France) maintained at $44{ }^{\circ} \mathrm{C}$ and a flow rate of $0.4 \mathrm{ml} / \mathrm{min}$ as detailed elsewhere [51]. At the end of the experiment, sky blue was perfused through the probe and rats killed by pentobarbital overdose to verify correct probe placement by histology in $50 \mu \mathrm{m}$ sections. Amino acid levels in fractional samples were expressed as a percentage of the mean value during 90-min baseline measurement immediately before treatment.

\section{Social Recognition}

Social recognition, a cortical-dependent working memory task based on olfactory discrimination of a novel from a familiar juvenile rat, considered relevant to dysfunction seen in psychiatric disorders $[52,53]$, was examined in adult rats. The procedure, described elsewhere [54, 55], evaluated the promnesic actions of compounds on a scopolamine-induced (1.25 mg/kg s.c.) deficit. Adult male Wistar rats were individually housed for 2 days before testing. On the test day, a juvenile was placed into the home cage for a 5-min session. A second 5-min session was performed immediately after the first one with the same juvenile reintroduced (for evaluation of the promnesic actions of ligands on a scopolamine-induced (1.25 mg/kg s.c.) deficit of recognition). The time (s) spent in active social investigation (i.e., the time spent by adult rat in sniffing, following, biting, jumping and crawling over or under the juvenile) during the first (T1) and the second (T2) session was monitored. The difference "T2-T1" was calculated and dose-response curves produced.

\section{Social Isolation}

The social isolation paradigm extensively validated in our laboratory [44 47, 56] produces a robust, reproducible behavioural syndrome including phenotype changes relevant to neurodevelopmental disorders with deficits in social behaviour and cognition such as schizophrenia, many of which are reversed by treatment with existing antipsychotics [46, 49]. The ability of acute injection of S18841 to reverse deficits in motor and cognitive behaviour was examined in this neurodevelopmental model. Rats were weaned at postnatal day (PND) 24, and half of each litter were housed either in social groups $(3-4$ per cage, $50 \times 33 \times 26 \mathrm{~cm})$ or alone $(41 \times$ $24 \times 20 \mathrm{~cm}$ ) for the rest of the study. Isolated rats were housed in the same holding room having auditory and olfactory contact but no physical interaction with conspecifics. Rats were 
isolated for 5 weeks before undergoing a battery of behavioural tasks, arranged in order of least to most aversive (to minimise any sequential effect on subsequent tasks) at approximately 1 -week intervals.

\section{Locomotor Activity}

Locomotor activity (ambulation and rearing) was measured using infrared beams during a $1-\mathrm{h}$ period as described before and in detail in the supplementary information [49, 57].

\section{Novel Object Recognition}

NOR is a visual learning and memory task that relies on innate preference of rats for novelty. It does not require previous training or re-enforcement [58] and is considered to have ethological relevance to human declarative memory $[53,59]$ impaired in schizophrenia. Furthermore, a recent translational study showed that the NOR discrimination ratio obtained in rat studies is a valid analogue of the sensitivity of human recognition memory in a visual-paired comparison task [60]. A $4 \mathrm{~h}$ inter-trial interval (ITI) prevents rats' ability to discriminate the novel from familiar object in our two-trial NOR task [61] that has been thoroughly validated. Acute treatment with dopamine $\mathrm{D}_{3}$ receptor antagonists, 5- $\mathrm{HT}_{6}$ antagonists and $\mathrm{mGluR}_{2 / 3}$ agonists reverse this impairment, while $\mathrm{D}_{2}$ receptor antagonists impair performance using a short ITI [49, 57, 61, 62], making it ideal choice to evaluate the effect of S14481. During the social isolation rearing study, a 2-h ITI was used with which group-housed vehicle-treated rats readily discriminate the novel from the familiar object [57]. In studies investigating the effect of drugs on a delay-induced impairment of NOR, a $4 \mathrm{~h}$ ITI was utilised so that normal, adult grouphoused vehicle-treated rats were unable to discriminate the novel from the familiar object [54]. Twenty-four hours before the test, rats were habituated to the arena (see "Locomotor Activity" for details) for $1 \mathrm{~h}$. On the test day, rats were briefly reacclimatized to the arena for $3 \mathrm{~min}$ before being returned to the home cage for $1 \mathrm{~min}$. During the familiarisation trial, two identical objects (plastic bottles, $8 \mathrm{~cm}$ high and $5 \mathrm{~cm}$ diameter, covered in white masking tape) were placed in opposite corners of the arena $(5 \mathrm{~cm}$ from the side and $10 \mathrm{~cm}$ from the end wall). The rat was returned to the arena for $3 \mathrm{~min}$, and exploration of each identical objects was recorded with stopwatches. After a 2 or $4 \mathrm{~h}$ ITI (in the social isolation and dose-response studies, respectively), the rat was returned to the arena with one familiar and one novel object (bottle wrapped with 4 black stripes $1.2 \mathrm{~cm}$ in width). During this second, choice, trial exploration of each object was recorded for $3 \mathrm{~min}$. Exploratory behaviour was defined as sniffing, licking, touching and direct attention to the object with active vibrissae while the nose is within $1 \mathrm{~cm}$ of the object. Climbing on or chewing the object was not considered as exploration.
Object exploration time during the choice trial was used to determine the discrimination ratio (time at novel-time at familiar/total choice trial object exploration).

\section{Conditioned Freezing Response}

CFR is a well-characterised, species conserved, hippocampal, amygdala and cortical dependent learning and memory task [63] utilised to index long-term associative memory of emotional based preference that is impaired in schizophrenia [64]. CFR is classically considered as part of the exemplary paradigms to investigate acute threat within the negative valence domain under the RDoC framework. However, the memory component of this paradigm, as investigated in this study, is clearly part of the cognitive system domain of the RDoC matrix highly pertinent to emotional memory and deficits thereof are seen in ASD and schizophrenia [65]. CFR was performed in a two-chamber shuttle box with light and dark sides $(27 \times$ $25 \times 25 \mathrm{~cm})$, separated by an automated door $(8 \times 8 \mathrm{~cm})$ and a wire grid floor (PanLab, Slab, Barcelona, Spain) using a 3 day test protocol described previously $[45,66]$. On the first (conditioning) day, rats received S18841 (2.5 or $10 \mathrm{mg} / \mathrm{kg}$ ) or vehicle ( $1 \mathrm{ml} / \mathrm{kg} \mathrm{s.c.)} 30 \mathrm{~min}$ before being placed in the light side of the chamber. The door opened after $30 \mathrm{~s}$ and latency to cross into the dark side was recorded using a floor sensor which closed the door (ShutAvoid, software v.1.8.2., Panlab S.L, USA). After $30 \mathrm{~s}$ in the dark side, a $5 \mathrm{~s}$ conditioning stimulus (CS, light and $3 \mathrm{kHz}, 89 \mathrm{~dB}$ tone) was followed by the unconditioned stimulus (US, $1 \mathrm{~s} 0.4 \mathrm{~mA}$ footshock during the last second of the CS) through the grid floor. A further two CS/US were delivered at $55 \mathrm{~s}$ intervals. Time spent freezing (completely immobile except for respiration in a hunched posture with inactive vibrissae) between shocks was recorded by stopwatch. Twenty-four and $48 \mathrm{~h}$ post-conditioning, rats were returned to the dark side for $300 \mathrm{~s}$ without CS/US and time spent freezing recorded again as an index of associative learning and memory. During the extinction trial ( $48 \mathrm{~h}$ post-conditioning), the CS alone was presented after $300 \mathrm{~s}$ and freezing recorded for a further $300 \mathrm{~s}$. Behaviour was also recorded through a camera in the roof of the CFR chamber using Ethovision (Noldus) to enable re-assessment if required.

\section{Microinjection for NOR}

In order to ascertain the importance of glycine receptors in the prefrontal cortex (PFC) in the cognitive effects of S14481, it was delivered by microinjection into this area. The PFC was selected because of the microdialysis data showing changes in either serine or glycine overflow occurred therein with administration of all the glycine agonists, partial agonists and reuptake inhibitors used herein. Lister hooded rats were anaesthetised with isoflurane $3.5 \%$ induction and maintained with $2 \%$ in $33 \% \mathrm{O}_{2}$ and $66 \% \mathrm{~N}_{2} \mathrm{O}$ ), placed in a stereotaxic frame to implant 
cannulae as described before [54]. Two 22-gauge guide cannulae, $1.5 \mathrm{~mm}$ apart projecting $3.5 \mathrm{~mm}$, were implanted above the PFC or in separate rats $5.0 \mathrm{~mm}$ apart projecting $5.0 \mathrm{~mm}$ above the striatum (Plastics One) at the following coordinates from bregma: $\mathrm{PFC} ; \mathrm{AP}+3.0, \mathrm{~L} \pm 0.7, \mathrm{DV}-2.3$ and striatum; $\mathrm{AP}+$ $0.5, \mathrm{~L} \pm 2.5, \mathrm{DV}-4.0$ [50]. Stylets (Plastics One) placed in the cannulae prevented occlusion. Rats were housed individually and allowed to recover for at least 1 week and handled daily to minimise stress associated with drug infusion. On the test day, rats were lightly restrained, stylets removed and sterile 28gauge injectors (Plastics One) used to bilaterally infuse $1 \mu \mathrm{l}$ drug or vehicle over 2 min with an infusion pump (Harvard Apparatus, Holliston, MA), 5 min before the NOR familiarisation trial. After behavioural testing, brains were removed and stored in paraformaldehyde for histological verification of the injection from coronal brain sections according to Paxinos and Watson [50].

\section{Materials}

S18841 (3-Hydroxy-4-imidazolidinone), glycine, D-serine, D-cycloserine, sarcosine and ORG24598 were dissolved in $0.9 \%(w / v)$ saline, $\mathrm{pH}$ normalized where appropriate and injected in a volume of $1 \mathrm{ml} / \mathrm{kg}$ s.c. 30 min prior to each task except for glycine which was dosed at a volume of $4 \mathrm{ml} / \mathrm{kg}$. L701,324 (7-chloro-4-hydroxy-3-(3-phenoxy) phenyl-2(H)quinolinone, $5 \mathrm{mg} / \mathrm{kg}$ in $4 \mathrm{ml} / \mathrm{kg}$ ) was suspended in distilled water with a few drops of Tween 80. CPP (3-(2carboxypiperazin-4-yl)propyl-1-phosphonic acid, $10 \mathrm{mg} / \mathrm{kg}$ in $1 \mathrm{ml} / \mathrm{kg}$ ) was dissolved in $0.9 \%(w / v)$ saline and $\mathrm{pH}$ normalised with $\mathrm{NaOH}$. L701,324 and CPP were injected i.p. 45 min prior to the NOR task. For microinjection into the PFC or striatum, S18841 was dissolved in artificial cerebrospinal fluid (aCSF) containing 10\% $w / v$ hydroxypropyl- $\beta$-cyclodextrin. The rat was lightly restrained and vehicle $(1 \mu \mathrm{l} /$ side) or S18841 injected at a rate of $0.5 \mu \mathrm{l} / \mathrm{min} 5 \mathrm{~min}$ prior to the behavioural analysis.

\section{Statistical Analysis}

In the social recognition task, the difference "T2-T1" was calculated and dose-response curves for promnesic properties analysed by one-way ANOVA followed by Dunnett's test. The time course of locomotor activity and rears and time spent exploring each object during the NOR choice trial were analysed using two-way repeated measures RM-ANOVA. Total activity counts and object exploration and discrimination ratio during NOR were analysed with two-way ANOVA (but one-way ANOVA for delay-induced NOR impairment studies). Following ANOVA $(P<0.05$ was considered significant in all cases), Fishers LSD or Dunnett's tests were used for post hoc analyses. All statistical analyses were performed using
GraphPad Prism v7.0 for Windows (GraphPad Software, San Diego, CA, USA) and SPSS (IBM SPSS Statistics v21, USA), and all data shown are mean \pm SEM. For microdialysis, time-course effects of drugs on amino acid levels was analysed by two-way ANOVA, with treatment as a betweensubjects factor and time a repeated measure, followed by Dunnett's post hoc tests. Dose effects of drugs were evaluated by comparing the area under the curve during the first $180 \mathrm{~min}$ after i.p. injection of the drug or vehicle and statistical analysis was carried out by a two-way ANOVA followed by Bonferroni's post hoc tests.

\section{Results \\ Effect of Glycine Modulatory Drugs on PFC Dialysate Levels of Amino Acids and Monoamines in Freely Moving Rats}

Given the pivotal role of PFC function in the modulation of working memory and the cognitive deficits seen in common psychiatric disorders, we used microdialysis to ascertain any common mode of action of the glycine-modifying drugs on neurotransmitter release therein. In freely moving rats, compared to vehicle, both glycine $\left(F_{(1,19)}=306.7, P<0.001\right)$ and the two GlyT1 inhibitors (sarcosine $F_{(1,18)}=710.3, P<0.0001$; and ORG24598, $\left.F_{(1,29)}=38.62, P<0.001\right)$ significantly increased (by 700, 150 and $130 \%$ above basal) glycine in PFC dialysates which peaked at 20 to $40 \mathrm{~min}$ (Fig. $1 \mathrm{a}$ and c). In contrast, glycine levels were unaffected by the glycine site agonists, D-serine or D-cycloserine or by S18841. D-serine $\left(F_{(1,9)}=10.00, P=0.0115\right)$ and D-cycloserine $\left(F_{(1,10)}=42.99\right.$, $P<0.001)$ were the only compounds to significantly elevate PFC D-serine levels (Fig. 1 b and d). No compound changed dialysate levels of glutamate, GABA, 5-HT or acetylcholine and only glycine and sarcosine elevated dopamine while glycine also elevated levels of noradrenaline (Table 1).

\section{Effect of Glycine Modulatory Drugs on Disruption of Social Recognition by Scopolamine}

We next compared the ability of all the glycine-modifying drugs to reverse a cholinergic-induced impairment of social discrimination of a novel from a familiar juvenile rat, a cortical-dependent working memory task to examine the functional consequence of the microdialysis data in adult rats. Social recognition was selected because of its perceived translational relevance to dysfunction in psychiatric disorders [53]. In the social recognition task with no intertrial delay, vehicle rats investigated the juvenile rat significantly less in $\mathrm{T} 2$ than T1, demonstrating social recognition memory (Fig. 2). However, adults given scopolamine $(1.25 \mathrm{mg} / \mathrm{kg} \mathrm{s.c.})$ prior to $\mathrm{T} 1$ spent a similar time investigating the juvenile in $\mathrm{T} 2$ 

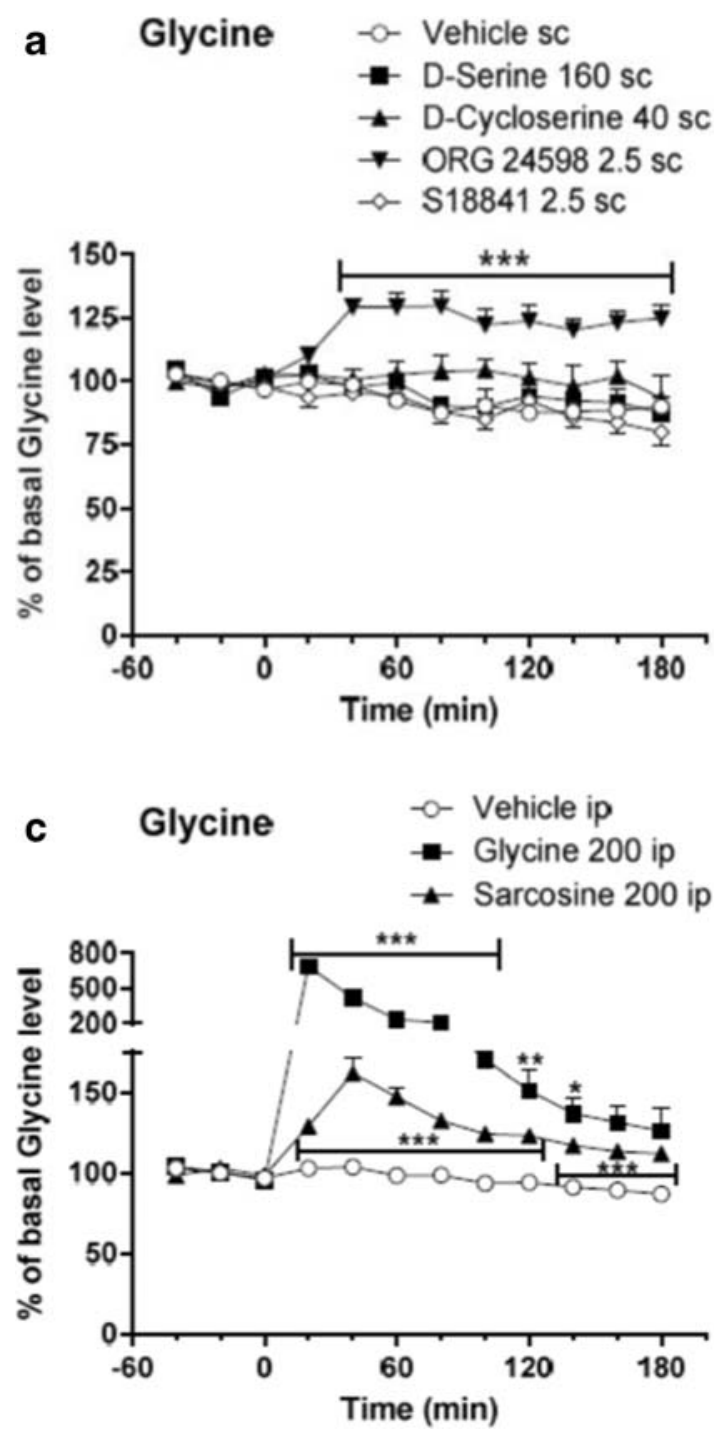

Fig. 1 Effect of glycine modulatory site agonists and glycine transport inhibitors on extracellular glycine (a and $\mathbf{c}$ ) and D-serine (b and d) levels in the prefrontal cortex of freely moving male Wistar rats. Microdialysis samples were taken for $180 \mathrm{~min}$ at 20-min intervals following acute systemic injection of S18841, D-cycloserine, ORG 24598, D-serine (all s.c.), glycine and sarcosine (both i.p.). Data is expressed as percentage change from a 40-min baseline taken prior to injection (mean $\pm \mathrm{SEM}, n=$ 5-26). Basal levels of glycine and D-serine were $8.28 \pm 1.07$ and $0.90 \pm$ $0.13 \mu \mathrm{M}$, respectively. Two-way ANOVA for $\mathbf{a}, \mathbf{b}$ and $\mathbf{c}$ (not $\mathbf{d}$ ) showed significant main effects of drug $(P=0.001)$, time $(P=0.001)$ and an interaction $(P=0.001)$. Significant two-way ANOVA was found in a:

and $\mathrm{T} 1$, indicative of impaired recognition memory compared to vehicle controls. The glycine site agonists, glycine (Fig. 2a, main effect of scopolamine, $F_{(1,50)}=53.14, P<0.001$; glycine, $F_{(3,50)}=3.93, P=0.0135$ and an interaction, $F_{(3,50)}=$ 3.73, $P=0.0170$ ), D-serine (Fig. $2 \mathrm{~b}$, scopolamine, $F_{(1,52)}=$ 24.32, $P<0.0001$; D-serine, $F_{(3,52)}=2.57, P=0.0644$ and interaction, $\left.F_{(3,52)}=2.66, P=0.045\right)$, D-cycloserine (Fig. $2 \mathrm{c}$, scopolamine, $F_{(1,51)}=31.59, P<0.0001 ;$ D-cycloserine, $F_{(3,51)}=5.93, P=0.0015$ and interaction, $F_{(3,51)}=7.22, P=$ 0.0004 ), and S18841 (Fig. 2f, scopolamine, $F_{(1,581)}=69.92$,
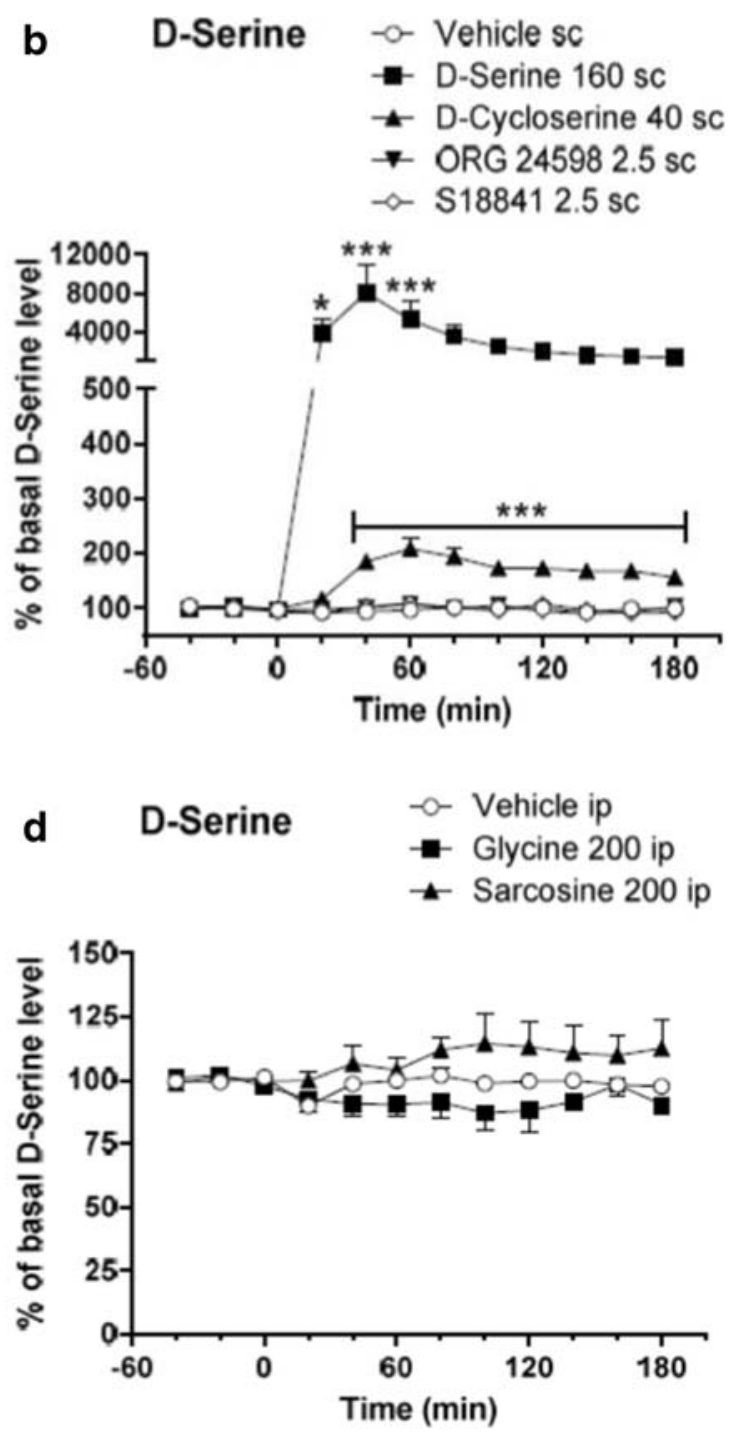

(effect on glycine levels) for ORG 24598: main effect of time ( $P$ $<0.001)$ and drug $(P<0.001)$ and interaction $(P<0.001)$; in $\mathbf{b}$ : (effect on D-serine levels) for D-cycloserine: main effect of time $(P<0.001)$, drug $(P<0.001)$ and interaction $(P<0.001)$ and D-serine: main effect of time $(P<0.001)$, drug $(P<0.001)$ and interaction $(P<0.001)$; and in $\mathbf{c}$ : (effect on glycine) for glycine: main effect of time $(P<0.001)$, drug $(P$ $<0.001)$ and interaction $(P<0.001)$ and sarcosine: main effect of time $(P<0.001)$, drug $(P<0.001)$ and interaction $(P<0.001) . * P<0.001$, $* * P<0.01, * * * P<0.001$ between drug and vehicle at that time, Bonferroni's multiple comparisons post hoc test

$P<0.0001 ; \mathrm{S} 18841, F_{(5,81)}=7.76, P<0.0001$ and interaction, $\left.F_{(5,81)}=6.85, P<0.0001\right)$ and the GlyT1 inhibitors, sarcosine (Fig. 2d, scopolamine, $F_{(1,61)}=21.55, P<0.0001$; sarcosine, $F_{(4,61)}=2.94, P=0.0274$ and interaction, $F_{(4,61)}=$ $6.90, P=0.0001$ ) and ORG24598 (Fig. 2e, scopolamine, $F_{(1,62)}=45.08, P<0.0001 ;$ ORG24598, $F_{(4,62)}=6.48, P=$ 0.0002 and interaction, $\left.F_{(4,62)}=7.76, P<0.0001\right)$ all reversed the impairment in social recognition caused by scopolamine, restoring the reduction in time spent exploring the juvenile in T2. Of particular note for every compound, the lowest 


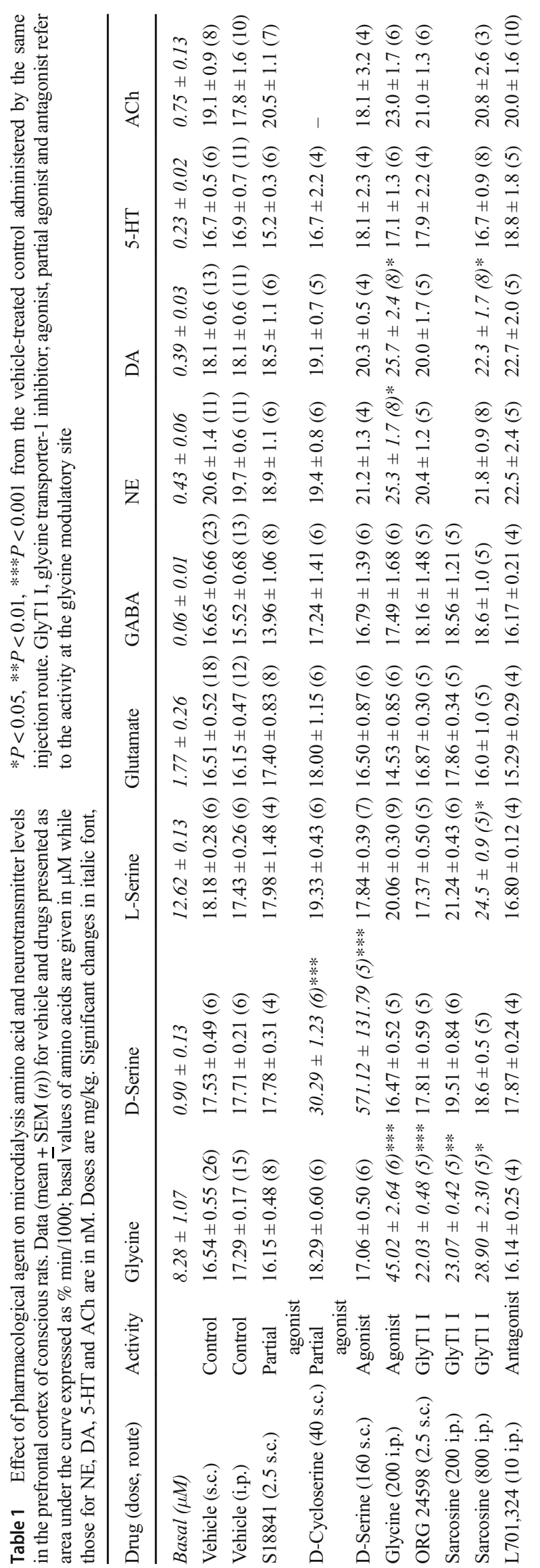




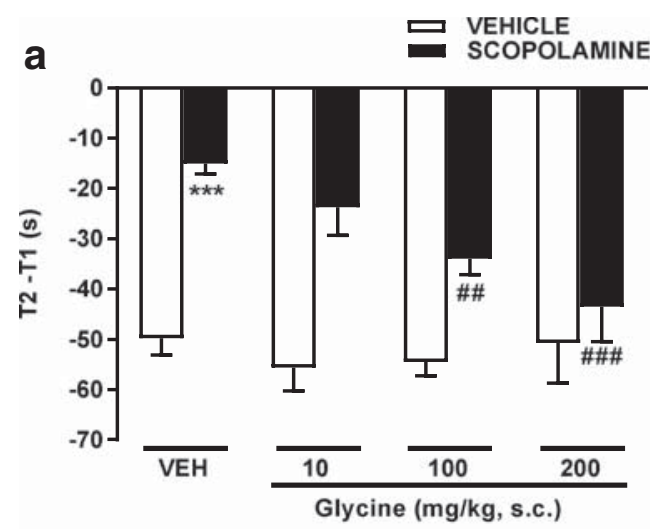

C

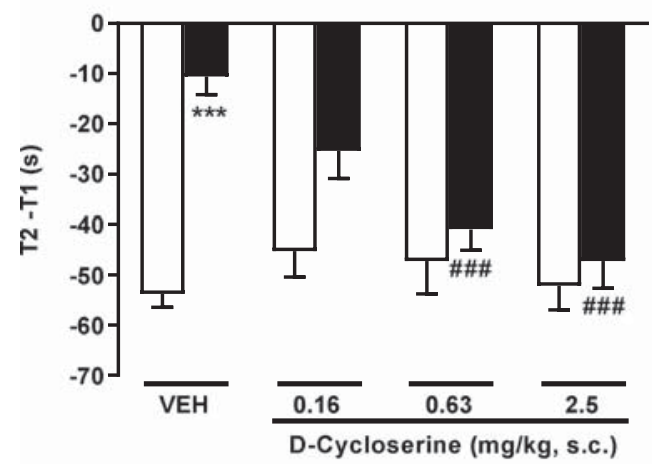

e

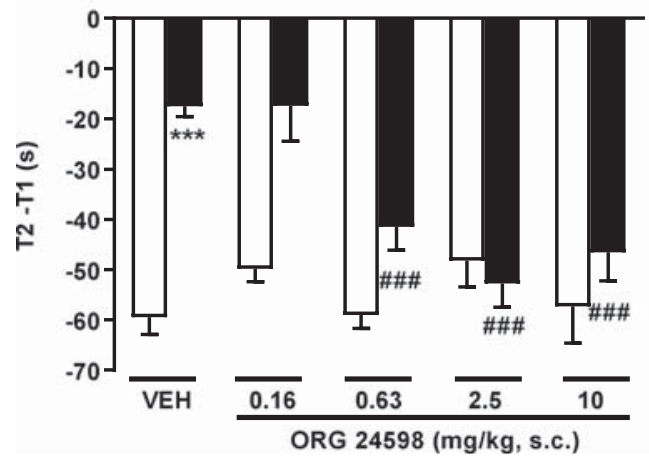

Fig. 2 Reversal of a scopolamine-induced deficit in social recognition in Wistar rats by a glycine, $\mathbf{b}$ D-serine, $\mathbf{c}$ D-cycloserine, $\mathbf{d}$ sarcosine, e ORG 24598 and $\mathbf{f ~ S 1 8 8 4 1 . ~ D a t a ~ s h o w n ~ ( T 2 - T 1 ) ~ i s ~ t h e ~ t i m e ~ d i f f e r e n c e ~ ( s ) ~ i n ~ t h e ~}$ exploration by the adult of the juvenile rat between the second (T2) and first (T1) trials. Values are means $\pm \mathrm{SEM}, n=5-13$. Rats were sequentially administered test drug (at doses indicated, s.c.) or vehicle $(0.9 \%(w /$ v) saline, $1 \mathrm{ml} / \mathrm{kg}$ ) $30 \mathrm{~min}$ prior to T1. Two-way ANOVA showed a for glycine: main effect of scopolamine $(P<0.001)$, glycine $(P=0.0135)$ and an interaction $(P=0.0170)$; $\mathbf{b}$ D-serine: main effect of scopolamine $(P<0.0001)$, D-serine $(P=0.0644)$ and interaction $(P=0.045)$; $\mathrm{D}$ -

dose to significantly increase social discrimination was lower than or equal to that shown to elevate glycine or D-serine levels in PFC microdialysates (Table 2). Furthermore, reversal of the recognition impairment occurred irrespective of whether the drug elevated glycine or D-serine, suggesting that either mechanism was effective, as is partial agonism at the glycine site.

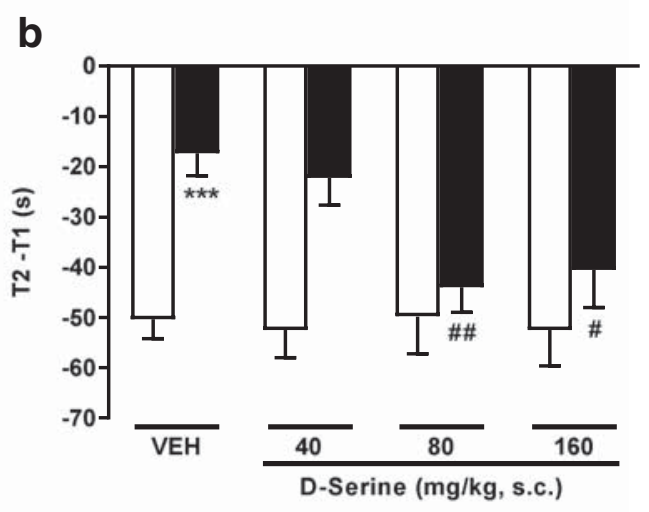

d

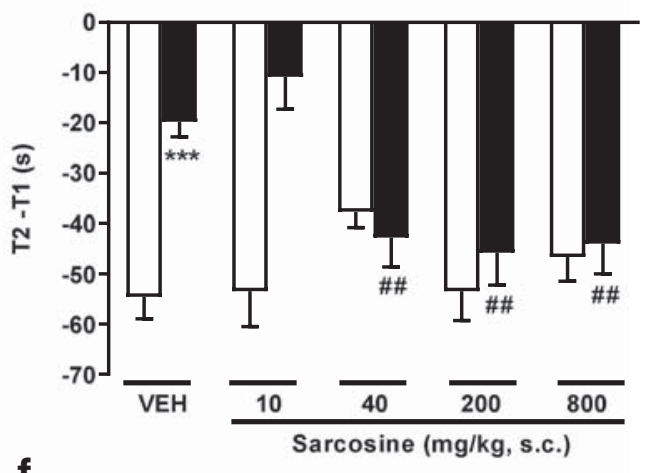

f

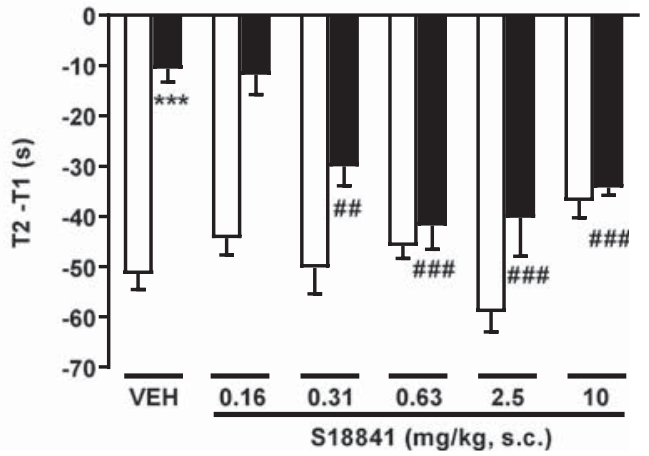

cycloserine: main effect of scopolamine $(P<0.0001)$, D-cycloserine $(P=0.0015)$ and interaction $(P=0.0004)$; d sarcosine: main effect of scopolamine $(P<0.0001)$, sarcosine $(P=0.0274)$ and interaction $(P=$ 0.0001); e ORG 24598: main effect of scopolamine $(P<0.0001)$, ORG $24598(P=0.0002)$ and interaction $(P<0.0001)$; and $\mathbf{f}$ S18841: main effect of scopolamine $(P<0.0001), \mathrm{S} 18841(P<0.0001)$ and interaction $(P<0.0001) . * * * P<0.001$ between vehicle/scopolamine and vehicle/ vehicle; ${ }^{\#} P<0.05,{ }^{\# \#} P<0.01$ and ${ }^{\# \# \#} P<0.001$ between drug/ scopolamine and vehicle/scopolamine Newman-Keuls post hoc test

\section{Effect of Glycine Modulatory Drugs on the Delay-Induced Impairment of Novel Object Recognition}

NOR is a visual learning and memory task considered to have ethological relevance to human declarative memory [53, 59] that is both PFC-dependent and impaired in schizophrenia, 
Table 2 Comparison of the dose of each glycine modulatory site agonist, partial agonist or GlyT1 inhibitor (GlyT1 I, as indicated in the activity column) to significantly (a) elevate prefrontal cortex (PFC) glycine and D-serine, (b) reverse scopolamine-induced impairment in social recognition (taken from $T_{2}-T_{1}$ active social investigation time, $s$ ) and (c) prevent the $4 \mathrm{~h}$ intertrial time delay-induced reduction in NOR (taken from choice trial discrimination ratio, (novel-familiar/total object exploration)). $* * P<0.01$ and $* * * P>0.001$ from vehicle control in that group of rats Dunnett's post hoc test following ANOVA. NOR = novel object recognition, i.p. $=$ intraperitoneal and s.c. $=$ subcutaneous

\begin{tabular}{|c|c|c|c|c|c|}
\hline \multirow[t]{2}{*}{ Drug } & \multirow[t]{2}{*}{ Activity } & \multicolumn{2}{|c|}{$\begin{array}{l}\text { Elevation in PFC microdialysate glycine or D- } \\
\text { serine dose } \mathrm{mg} / \mathrm{kg} \text { and route of injection }\end{array}$} & \multirow[t]{2}{*}{$\begin{array}{l}\text { Reversal of scopolamine-impaired } \\
\text { social recognition dose } \mathrm{mg} / \mathrm{kg} \text { s.c. }\end{array}$} & \multirow[t]{2}{*}{$\begin{array}{l}\text { Reversal of time-delay } \\
\text { reduction in NOR dose } \mathrm{mg} / \mathrm{kg} \text { i.p. }\end{array}$} \\
\hline & & Glycine & D-serine & & \\
\hline Glycine & Agonist & 200 i.p.*** & - & $100 * *$ & $160 *$ \\
\hline D-Serine & Agonist & - & 160 s.c. $* * *$ & $80 * *$ & $40 * *$ \\
\hline D-Cycloserine & Partial agonist & - & 40 s.c. $* * *$ & $0.63 * * *$ & $2.5^{*}$ \\
\hline Sarcosine & GlyT1 I & 200 i.p.*** & - & $40^{* *}$ & $200 *$ \\
\hline ORG24598 & GlyT1 I & 2.5 s.c. $* * *$ & - & $0.63 * * *$ & $2.5 * *$ \\
\hline S18841 & Partial agonist & - & - & $0.31 * *$ & $10 * *$ \\
\hline
\end{tabular}

and its selection is thoroughly considered in the discussion. We therefore performed dose-response studies with all the glycine-modifying compounds to establish their ability to improve a time-delay-induced impairment in NOR. With vehicle injection in all studies, rats were unable to distinguish the novel from the familiar object in the choice trial (Fig. $3 \mathrm{a}, \mathrm{c}$, e, $g$ and i). However, the highest two doses of every agonist or glycine reuptake inhibitor increased the time spent exploring the novel over the familiar object, and even the lowest dose $(2.5 \mathrm{mg} / \mathrm{kg})$ of D-cycloserine produced a significant increase. With glycine, D-serine and sarcosine $\left(F_{(3,44)}=2.709, P=\right.$ $0.057, F_{(3,44)}=7.45, P<0.001$, and $F_{(3,44)}=10.27, P$ $<0.001$, respectively), the significant increase in novel object exploration was dose-related, while the improvement seen with D-cycloserine $\left(F_{(3,44)}=6.518, P<0.01\right)$ was similar at all three doses and with ORG24598 $\left(F_{(3,44)}=8.23, P<0.001\right)$ only apparent at the highest two doses.

Analysis of the choice trial discrimination ratio data (Fig. 3 b, $\mathrm{d}, \mathrm{f}, \mathrm{h}$ and $\mathrm{j}$ ) from the same rats confirmed improvement in object discrimination predicted from raw exploration times. In all groups, the discriminated ratio was at or close to chance following vehicle and significantly increased with glycine $\left(F_{(3,44)}=\right.$ $3.17, P<0.05 ; P<0.05$ two highest doses $)$, D-serine $\left(F_{(3,44)}=\right.$ 9.64, $P<0.001 ; P<0.01$ and $P<0.001$ with 40 and $160 \mathrm{mg} / \mathrm{kg}$, respectively), D-cycloserine $\left(F_{(3,44)}=3.73, P<0.05 ; P<0.05\right.$ with all doses $)$, sarcosine $\left(F_{(3,44)}=7.88, P<0.001 ; P<0.001\right.$, highest dose only) and ORG24598 $\left(F_{(3,44)}=8.72, P<0.001 ; P\right.$ $<0.01$ and $P<0.05$ at 2.5 and $5 \mathrm{mg} / \mathrm{kg}$, respectively). Thus, as with social recognition, the minimum dose to improve NOR was equivalent to, or lower than, that found to elevate either PFC glycine or D-serine in microdialysates (Table 2), consistent with mechanistic association.

No dose of any drug caused a preferential exploration of either object during the familiarisation trial (Table 3), although with sarcosine ANOVA showed a significant $\left(F_{(3,44)}=10.27\right.$, $P<0.001)$ location $\times$ drug interaction. Furthermore, only in the
D-serine group was there any main effect of drug on total object exploration time in the familiarisation trial $\left(F_{(3,44)}=2.98, P\right.$ $<0.05)$ and this was not dose-related. In all other groups, there was no effect of drug treatment on total exploration in either familiarisation or choice trials (Table 3). Therefore, alteration of choice trial object exploration by all five drugs resulted from redistribution of attention towards the novel object, consistent with a specific effect on visual learning and memory and not a reduction in attention to both objects.

Acute pretreatment with the glycine site partial agonist, $\mathrm{S} 18841$ (0.63 to $10 \mathrm{mg} / \mathrm{kg}$ s.c.), reversed a time delayinduced impairment in NOR (Fig. $4 \mathrm{a}$ and b). With a $4 \mathrm{~h}$ ITI, vehicle-treated rats were unable to distinguish the novel from the familiar object in the choice trial (Fig. 4a) as expected [54]. S18841 produced a dose-related restoration of preferential novel object exploration (Fig. 4a object $\times \mathrm{S} 18841 ; F_{(3}$, $40)=3.02, P<0.05)$, confirmed by the discrimination ratio (Fig. 4b, $\left.F_{(3,40)}=3.70, P<0.05\right)$ being significantly $(P$ $<0.01)$ greater than vehicle with the highest dose $(10 \mathrm{mg} / \mathrm{kg})$. There was no preference for either object and no main effect of drug treatment during the familiarisation trial (Table 4). Similarly S18841 had no effect on total object exploration during either the familiarisation (Table 4) or choice trials confirming a specific pro-cognitive effect of S18841.

\section{Prevention of the Pro-cognitive Effect of S18841 on NOR by Blockade of NMDA Receptors}

To establish the downstream role of NMDA receptor activation in the effect of S18841 on recognition memory, we showed that the glycine modulatory site antagonist, L701,324, and the NMDA receptor antagonist, CPP, completely prevented the reversal of impairment of NOR by S18841 (Fig. $4 \mathrm{c}$ and d). Akin to data in the dose-response study, vehicle-treated rats were unable to discriminate novel and familiar objects but S18841 (10 mg/kg) restored novel 


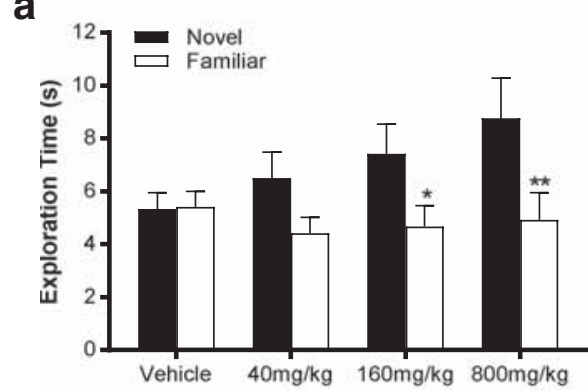

Glycine

b

C

\section{D-Serine}
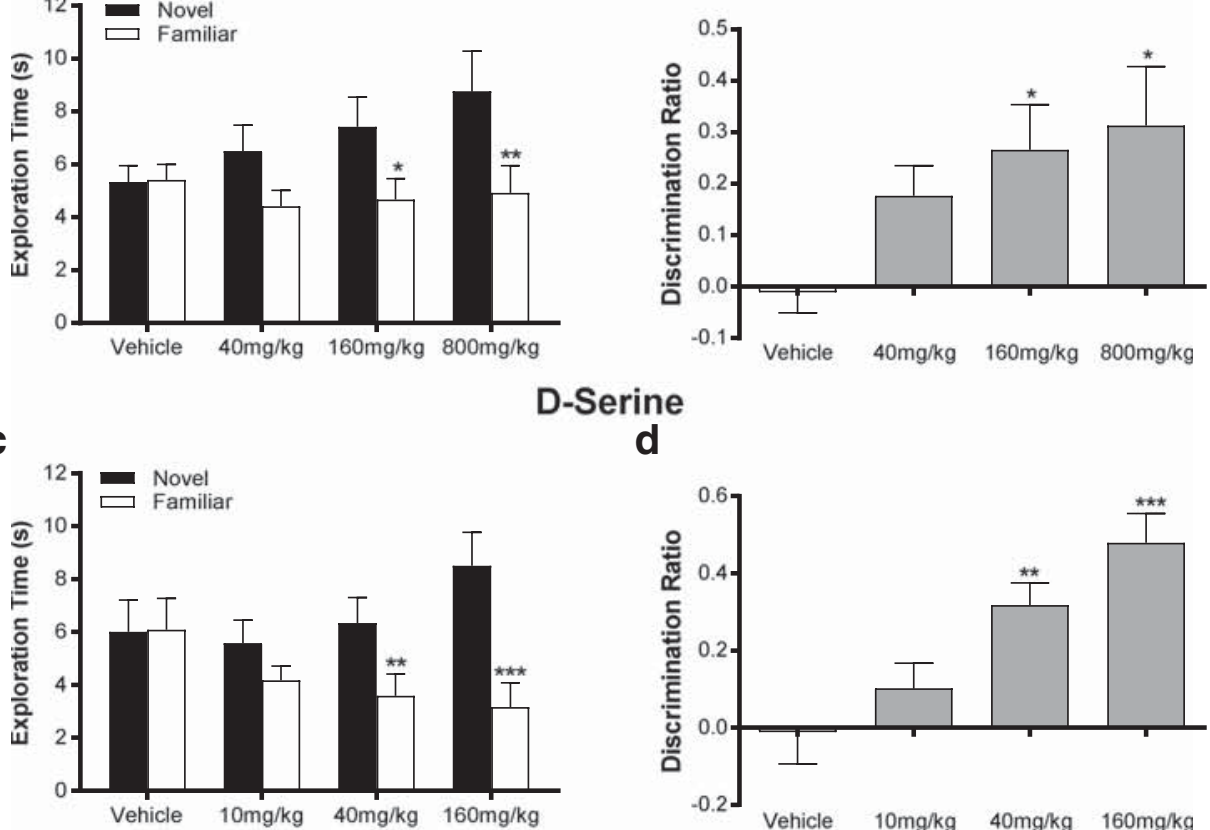

d

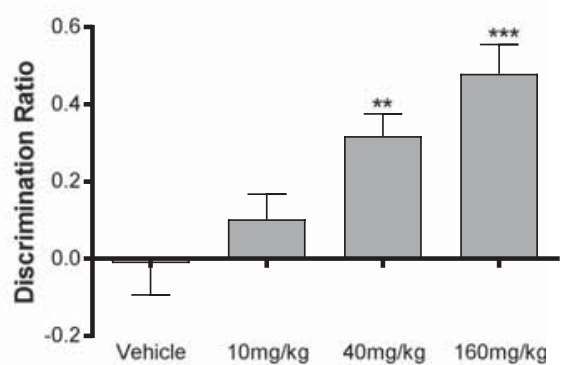

e

D-Cycloserine
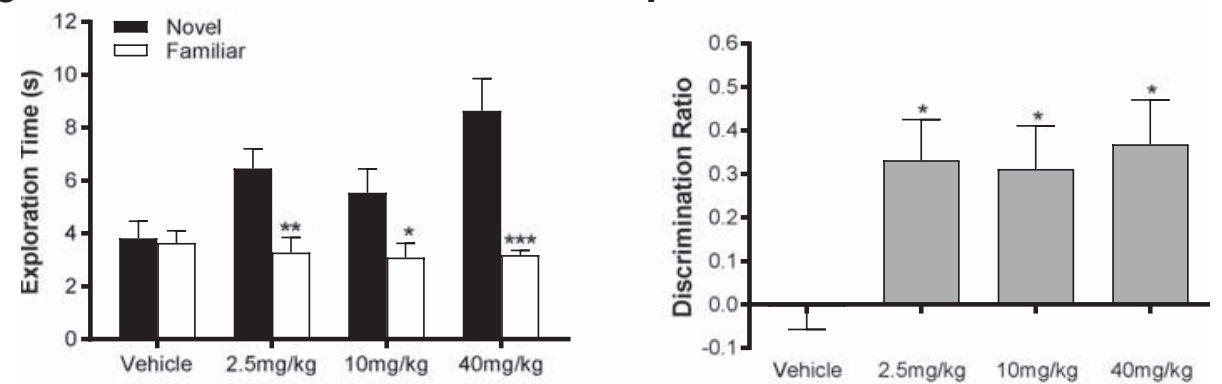

Sarcosine

g

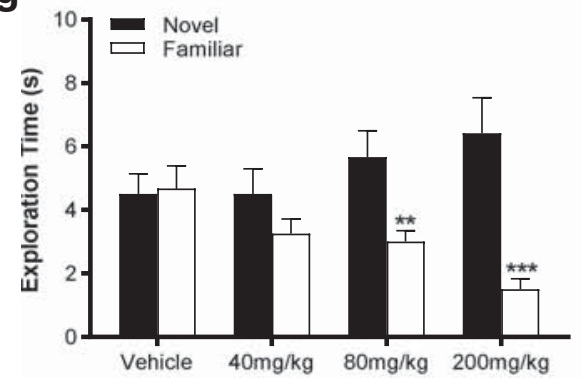

h

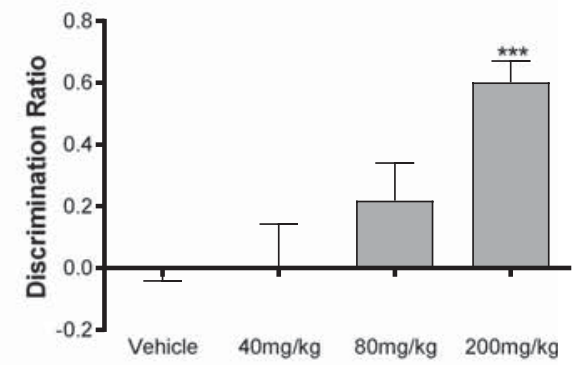

ORG 24598

i

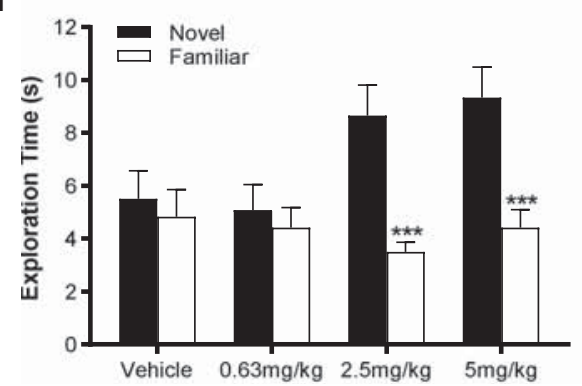

j

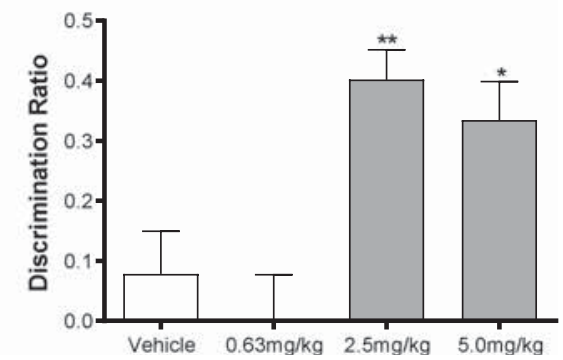


Fig. 3 Ability of glycine receptor agonists (a-f) and glycine reuptake inhibitors $(\mathbf{g}-\mathbf{j})$ to reverse natural forgetting in a $4-\mathrm{h}$ intertrial interval novel object recognition paradigm. Comparison of the effect of glycine (a and b, 40-800 mg/kg, $4 \mathrm{ml} / \mathrm{kg}$ ), D-serine (c and d, 10-40 mg/kg, $1 \mathrm{ml} /$ $\mathrm{kg}$ ), D-cycloserine (e and f , 2.5-40 mg/kg, $1 \mathrm{ml} / \mathrm{kg}$ ), sarcosine (g and $\mathbf{h}$, $40-200 \mathrm{mg} / \mathrm{kg}, 1 \mathrm{ml} / \mathrm{kg}$ ) and ORG 24598 (i and j, $0.63-5 \mathrm{mg} / \mathrm{kg}, 1 \mathrm{ml} / \mathrm{kg}$ ) injected s.c. $30 \mathrm{~min}$ prior to the familiarisation trial in Lister hooded rats ( $n=12$ unless stated, data shown as mean \pm SEM). a, c, e, g, i Actual novel and familiar object exploration times (s) during the second choice trial; $* P<0.05, * * P<0.01, * * * P<0.001$ significantly different from novel object in same treatment group, Bonferroni post hoc following repeated measures ANOVA. b, d, f, h, j Derived discrimination ratio (novel object exploration-familiar object exploration/total object exploration); $* P<0.05, * * P<0.01, * * * P<0.001$ significantly different from vehicle control, Dunnett's post hoc. In a, RM-ANOVA showed that the object $\times$ glycine treatment interaction just failed to reach significance $(P=0.057)$. b ANOVA showed a significant main effect of glycine treatment $(P<0.05)$. c Significant object $\times$ D-serine interaction $(P<0.001)$. d Significant main effect of D-serine $(P<0.001)$. e Significant object $\times D$ cycloserine interaction $(P<0.01, n=11)$. f Significant effect of Dcycloserine $(P<0.05, n=11)$. g Significant object $\times$ sarcosine interaction $(P<0.001)$. h Significant main effect of D-serine treatment $(P<0.001)$. i Significant object $\times$ ORG 24598 treatment interaction $(P<0.001)$. j Significant effect of ORG 24598 treatment $(P<0.001)$

Table 3 Object exploration during familiarisation and choice trials with glycine agonists and GlyT1 inhibitors, accompanying Fig. 3. Time (s, mean (SEM)) spent exploring (from left to right) front and back object and both objects during the (first) familiarisation trial and total time exploring both objects in the (second) choice trial in the novel object recognition test. For each glycine site agonist or glycine transporter-1 inhibitor, three doses (as stated) were compared to the effect of vehicle (s.c.) given in a balanced quasi-random order over 4 weeks in five separate groups of group-housed male Lister Hooded rats. Following D-serine object preference $\left(\right.$ Fig. 4 c object $\times \mathrm{S} 18841 ; F_{(1,40)}=12.29, P$ $<0.01)$. Of note, co-treatment with either CPP or L701,324 prevented the $\mathrm{S} 18841$-induced reversal (object $\times \mathrm{CPP} /$ L701,324; $F_{(2,44)}=14.660, P<0.001$. Furthermore, the significant increase in discrimination ratio in the $\mathrm{S} 18841 /$ vehicle group (Fig. 4d, $F_{(1,44)}=6.79, P<0.05$ ) was abolished by S18841/CPP and S18841/L701,324 combinations $\left(F_{(2,40)}=\right.$ 8.82, $P<0.01)$, the ratio being significantly less $(P<0.001$ and $P<0.01$, respectively) with CPP and L701,324 than with vehicle/S18841 treatment. Both CPP and L701,324 reduced total object exploration in the familiarisation trial (Table 3; $\mathrm{S} 18841 ; F_{(1,44)}=4.56, P<0.05, \mathrm{CPP} / \mathrm{L} 701,324 ; F_{(1,44)}=$ $3.29, P<0.05)$, but there were no significant changes in total choice trial exploration. Despite total exploration being reduced, there was no object preference (Table 4) and neither treatment effected the distribution of object exploration during the familiarisation trial.

\section{Reversal of Delay-Dependent Impairment of NOR by Intra-PFC S18841}

Consistent with the involvement of the PFC in the procognitive effects of S18841, bilateral PFC microinjection of

administration there was a significant main effect of drug treatment on total object exploration during the familiarisation trial $(P<0.05)$. There was no preference for the location of the object during the familiarisation trial in any drug group, but following treatment with sarcosine there was a significant location $\mathrm{x}$ drug interaction $(P<0.05)$. There was no significant effect of any drug on total exploration during the choice trial (all $P>0.05)$. $* P<0.05$ from vehicle at that time point, Dunnett's post hoc following ANOVA

\begin{tabular}{|c|c|c|c|c|c|}
\hline \multirow[b]{2}{*}{ Drug } & \multirow[b]{2}{*}{ Dose } & \multicolumn{2}{|c|}{ Familiarisation trial } & \multicolumn{2}{|l|}{ Choice trial } \\
\hline & & Front object (s) & Back object (s) & Total exploration (s) & Total exploration (s) \\
\hline \multirow[t]{4}{*}{ Glycine $(n=12)$} & Vehicle & $5.5(0.4)$ & $5.7(0.6)$ & $11.2(0.8)$ & $10.8(1.1)$ \\
\hline & $40 \mathrm{mg} / \mathrm{kg}$ & $6.9(0.9)$ & $8.0(1.0)$ & $14.9(1.8)$ & $10.9(1.5)$ \\
\hline & $160 \mathrm{mg} / \mathrm{kg}$ & $7.0(0.8)$ & $6.2(0.6)$ & $13.2(1.2)$ & $12.1(1.6)$ \\
\hline & $800 \mathrm{mg} / \mathrm{kg}$ & $6.9(0.9)$ & $6.3(0.9)$ & $13.2(1.6)$ & $13.7(2.1)$ \\
\hline \multirow[t]{4}{*}{ D-Serine $(n=12)$} & Vehicle & $5.8(1.0)$ & $5.5(0.8)$ & $11.3(1.7)$ & $12.1(2.3)$ \\
\hline & $10 \mathrm{mg} / \mathrm{kg}$ & $6.7(0.7)$ & $7.9(0.8)$ & $14.6(1.2)$ & $9.8(1.3)$ \\
\hline & $40 \mathrm{mg} / \mathrm{kg}$ & $9.0(0.9)$ & $8.6(1.3)$ & $17.7(2.2)^{*}$ & $9.9(1.7)$ \\
\hline & $160 \mathrm{mg} / \mathrm{kg}$ & $5.7(0.9)$ & $6.7(0.6)$ & $12.3(1.3)$ & $11.7(1.9)$ \\
\hline \multirow[t]{4}{*}{ D-Cycloserine $(n=11)$} & Vehicle & $7.5(0.9)$ & $7.6(0.8)$ & $15.1(1.5)$ & $7.5(1.1)$ \\
\hline & $2.5 \mathrm{mg} / \mathrm{kg}$ & $6.3(0.6)$ & $6.5(0.6)$ & $12.7(1.0)$ & $9.7(1.1)$ \\
\hline & $10 \mathrm{mg} / \mathrm{kg}$ & $5.5(0.7)$ & $6.7(0.7)$ & $12.2(1.2)$ & $8.6(1.3)$ \\
\hline & $40 \mathrm{mg} / \mathrm{kg}$ & $6.5(0.8)$ & $6.9(1.4)$ & $13.5(2.2)$ & $11.8(1.2)$ \\
\hline \multirow[t]{4}{*}{ Sarcosine $(n=12)$} & Vehicle & $6.0(0.7)$ & $4.1(0.4)$ & $10.1(1.0)$ & $9.2(1.3)$ \\
\hline & $40 \mathrm{mg} / \mathrm{kg}$ & $4.5(0.4)$ & $4.8(0.6)$ & $9.3(0.8)$ & $7.8(1.2)$ \\
\hline & $80 \mathrm{mg} / \mathrm{kg}$ & $5.1(0.6)$ & $5.3(0.4)$ & $10.3(0.8)$ & $8.7(1.1)$ \\
\hline & $200 \mathrm{mg} / \mathrm{kg}$ & $5.5(0.4)$ & $5.6(0.5)$ & $11.1(0.7)$ & $7.9(1.3)$ \\
\hline \multirow[t]{4}{*}{ ORG $24598(n=12)$} & Vehicle & $5.0(0.8)$ & $6.1(0.8)$ & $11.1(1.5)$ & $10.3(2.0)$ \\
\hline & $0.63 \mathrm{mg} / \mathrm{kg}$ & $5.9(1.0)$ & $7.2(1.0)$ & $13.1(1.6)$ & $9.5(1.7)$ \\
\hline & $2.5 \mathrm{mg} / \mathrm{kg}$ & $8.4(1.2)$ & $7.4(1.1)$ & $15.8(2.1)$ & $12.2(1.4)$ \\
\hline & $5 \mathrm{mg} / \mathrm{kg}$ & $6.9(0.9)$ & $6.9(0.7)$ & $13.8(1.3)$ & $13.8(1.5)$ \\
\hline
\end{tabular}




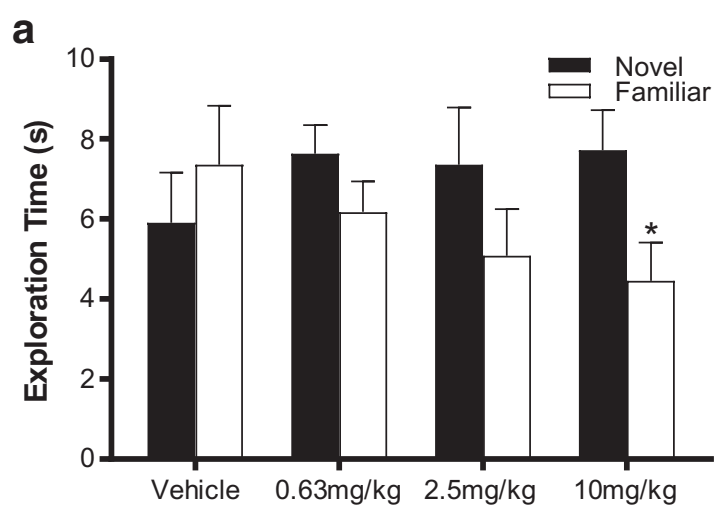

b
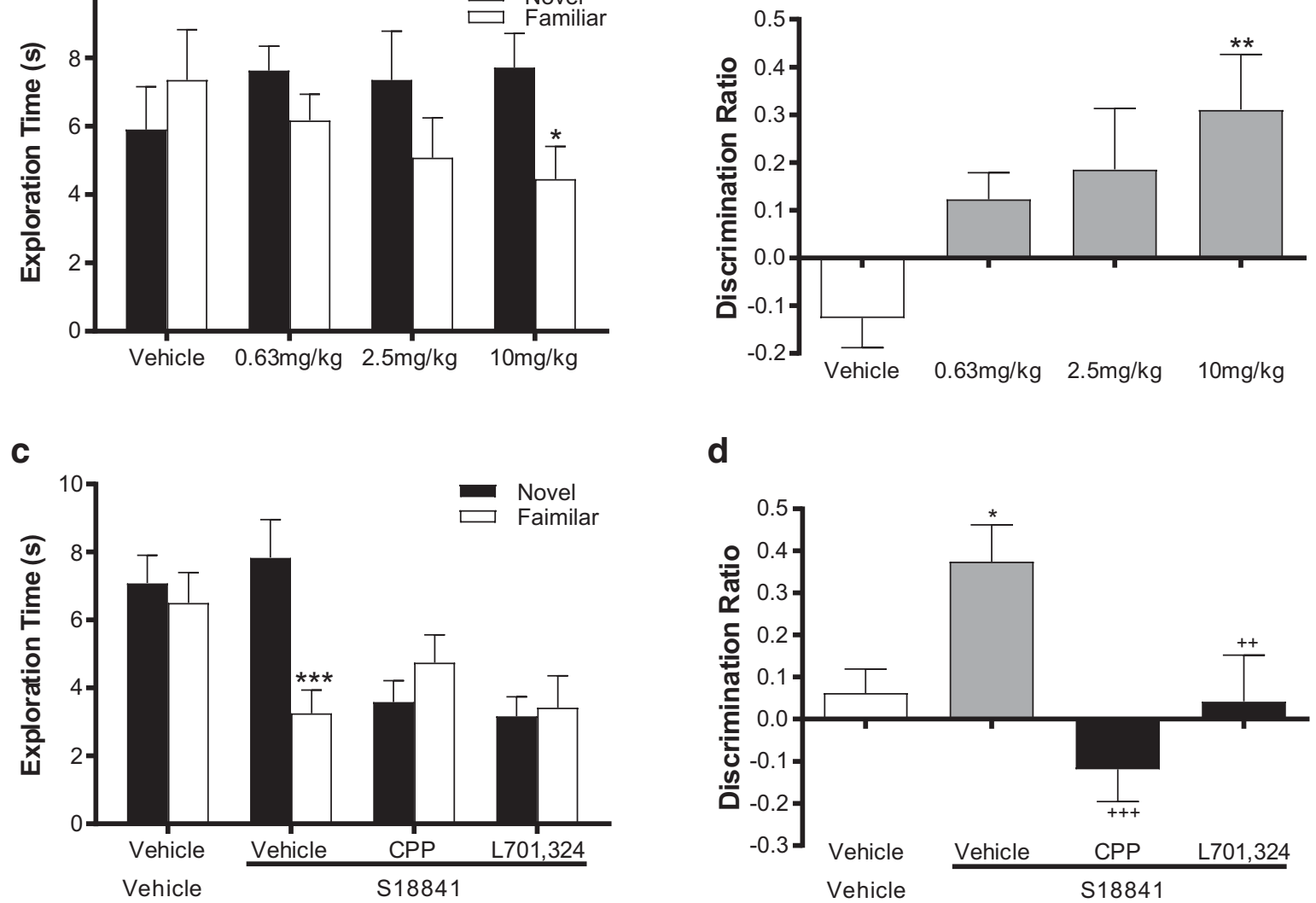

d

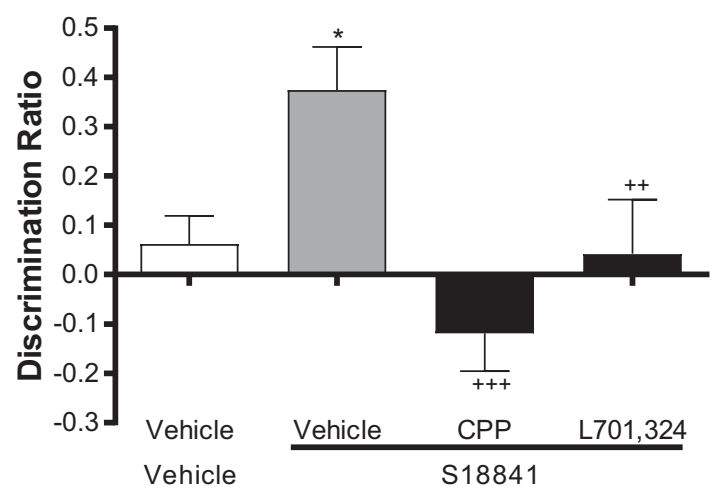

e

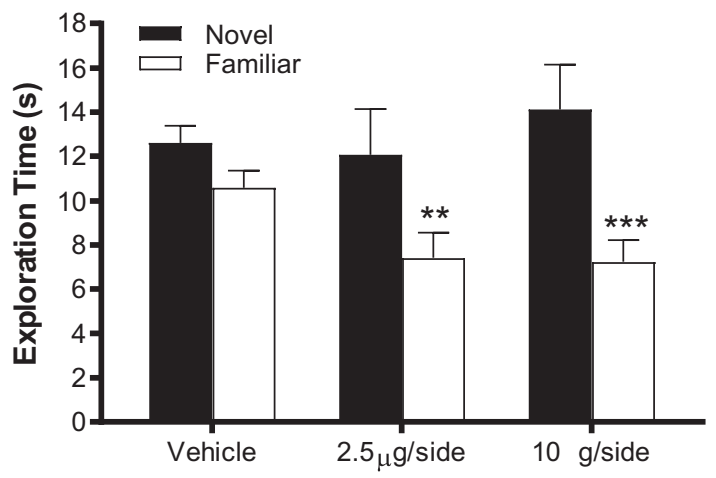

f

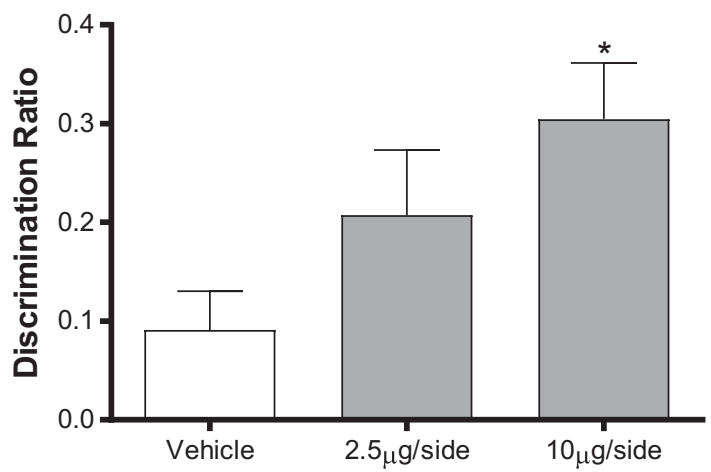

g

h
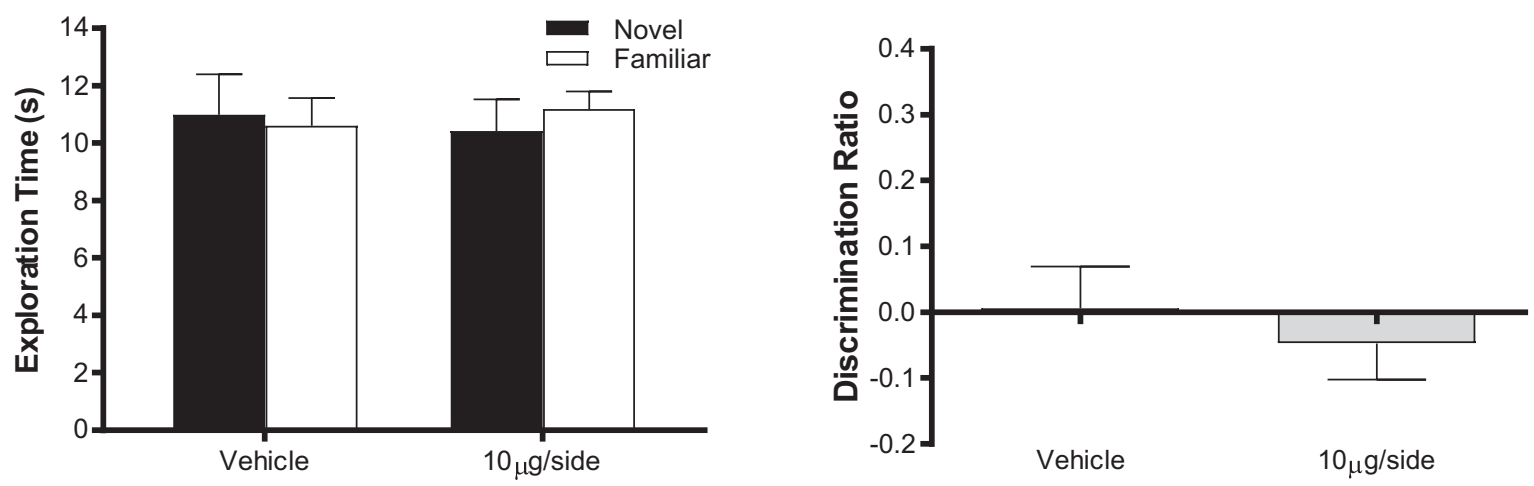
Fig. 4 Restoration of a time-delay impairment (natural forgetting) in novel object recognition by the partial glycine agonist, S18841, is prevented by the glycine antagonist, L701,324, and the NMDA receptor antagonist, CPP. S18841 (in a and b $0.63-10 \mathrm{mg} / \mathrm{kg}$, in $\mathbf{c}$ and $\mathbf{d} 10 \mathrm{mg} / \mathrm{kg}$ ) or vehicle $(1 \mathrm{ml} / \mathrm{kg})$ injected s.c. $30 \mathrm{~min}$ prior to the familiarisation trial in Lister hooded rats. CPP (20 mg/kg, $1 \mathrm{ml} / \mathrm{kg}), \mathrm{L} 701,324(10 \mathrm{mg} / \mathrm{kg}, 4 \mathrm{ml} /$ $\mathrm{kg})$ or vehicle $(1 \mathrm{ml} / \mathrm{kg})$ injected i.p. $20 \mathrm{~min}$ prior to the familiarisation trial in $\mathbf{c}$ and $\mathbf{d}$. The partial glycine agonist, S18841, delayed natural forgetting in the novel object discrimination paradigm when discretely injected into the prefrontal cortex (e and f) but not the striatum ( $\mathbf{g}$ and $\mathbf{h}$ ). $\mathrm{S} 18841(2.5 \mu \mathrm{g}$ or $10 \mu \mathrm{g} / \mathrm{side})$ or vehicle $(1 \mu \mathrm{l} / \mathrm{side})$ injected $5 \mathrm{~min}$ prior to the familiarisation trial in group-housed male Lister hooded rats. Data presented as mean \pm SEM. a, c, e, g Actual novel and familiar object exploration time (s) during the second choice trial. $\mathbf{b}, \mathbf{d}, \mathbf{f}, \mathbf{h}$ Derived discrimination ratio (novel object exploration-familiar object exploration/total object exploration). In a, RM-ANOVA showed a significant object $\times \mathrm{S} 18841$ treatment interaction $(P<0.05), * P<0.05$ from novel object in same treatment group, Bonferroni post hoc. b ANOVA showed a significant effect of S18841 treatment $(P<0.05), * * P<0.01$ from vehicle, Dunnett's post hoc. c RM-ANOVA significant object $\times$ S18841 treatment $(P<0.01)$ and object $\times$ CPP/L701,324 interactions $(P<0.001), * * * P<0.001$ from novel object in same treatment group, Bonferroni post hoc. d ANOVA showed a significant effect of S18841 treatment $(P<0.05)$ and a significant effect of CPP/L701,324 $(P<0.01)$, $* * P<0.01$ from vehicle/vehicle; ${ }^{++} P<0.01,{ }^{+++} P<0.001$ from $\mathrm{S} 18841 /$ vehicle, Fishers LSD post hoc. e RM-ANOVA showed a significant object $\times \mathrm{S} 18841$ treatment interaction $(P<0.05), * * P<0.01$, $* * * P<0.001$ from novel object in same treatment group, Bonferroni post hoc. $\mathbf{f}$ ANOVA showed a significant effect of S18841 treatment $(P<0.05)$, $* P<0.05$ from vehicle, Dunnett's post hoc. g RM-ANOVA no significant object $\times \mathrm{S} 18841$ treatment interaction $(P=0.510)$. h, ANOVA showed a no significant effect of S18841 treatment $(P=0.531)$

S18841 reversed the delay-dependent impairment of NOR (Fig. $4 \mathrm{e}$, object $\times \mathrm{S} 18841 ; F_{(2,29)}=4.11, P<0.05$ ) such that rats given either dose spent significantly more $(P<0.01$ and $P<0.001)$ time exploring the novel object. PFC injection of S18841 also increased the derived discrimination ratio (Fig. 4f, $\left.F_{(2,29)}=4.68, P<0.05\right)$ such that it was significantly greater than vehicle $(P<0.05)$. In contrast, injecting S18841 into the striatum at the higher dose failed to enhance exploration of the novel object (Fig. 4g) or alter the discrimination ratio (Fig. 4h). Bilateral microinjections of S18841 into the PFC or striatum had no effect on total object exploration during either the familiarisation or choice trials (Table 4), emphasising that improvement in visual recognition memory was not due to changes in locomotor activity or inattention to the objects during acquisition. In addition, irrespective of the site of S18841 microinjection, it did not alter the distribution of object exploration during the familiarisation trial (Table 4). Histological analysis confirmed the site of the microinjections in all rats (see online resource; Fig. S1).

\section{Effect of S18841 upon Hyperactivity of Isolation-Reared Rats}

Commencing 5 weeks after weaning, rats underwent a battery of behavioural tasks (Fig. 5a), the first being placed in an unfamiliar chamber without drug administration to confirm that isolation induced the expected novelty-induced hyperactivity (supplementary Fig. S2A, $\left.F_{(1,48)}=16.70, P<0.001\right)$. Isolation-reared rats showed greater horizontal activity over time (time $\times$ housing; $\left.F_{(11,528)}=3.29, P<0.001\right)$ when introduced to the chamber compared to their group-housed littermates, confirming development of the 'isolation syndrome'. In addition to hyperactivity, as expected, isolated rats displayed significantly more rears over $1 \mathrm{~h}$ than grouphoused controls (online resource; Fig. S2B).

Six weeks after weaning, rats were pretreated with S18841 (2.5 or $10 \mathrm{mg} / \mathrm{kg})$ or vehicle before being reintroduced into the chamber (Fig. 5a). As expected, the socially isolated rats were hyperactive (Fig. $5 \mathrm{~b}, F_{(1,45)}=$ $14.22, P<0.001$ ) but $\mathrm{S} 18841$ had no significant effect on locomotor activity in group-housed or isolated rats. Similarly, the increase in total rears in the isolated rats (Fig. 5c, $F_{(1,45)}=16.42, P<0.001$ ) was unaltered by S18841. This suggests that the partial glycine agonist may have little effect on the augmentation of ventral tegmental dopaminergic activation of the nucleus accumbens thought to contribute to the isolation-induced hyperactive response to a novel environment.

\section{Reversal of NOR Deficits in Isolation-Reared Rats by $\mathrm{S} 18841$}

The effect of S18841 on NOR in isolation-reared rats was examined to ascertain if it could reverse a neurodevelopmental impairment in visual recognition memory (Fig. $5 \mathrm{~d}$ and e). S18841 reversed the impairment of NOR seen in isolation-reared rats, ANOVA showing an object $\times \mathrm{S} 18841$ treatment $\left(F_{(2,45)}=3.84, P<0.05\right)$ and object $\times$ housing $\times \mathrm{S} 18841$ treatment $\left(F_{(1,45)}=22.89, P\right.$ $<0.001$ ) interaction (Fig. 5d). Analysis of the derived discrimination ratio (Fig. 5e) showed a significant main effect of housing $\left(F_{(1,45)}=7.06, P<0.05\right)$, confirming that this index of NOR was also significantly greater in isolated rats treated with either dose of S18841 $(2.5 \mathrm{mg} / \mathrm{kg} ; P<0.01$, $10 \mathrm{mg} / \mathrm{kg} ; P<0.001)$ than in vehicle-treated isolates, consistent with the drug-induced reversal of the neurodevelopmental cognitive impairment. Rats did not show any preferential exploration of the identical objects in the familiarisation trial (Table 5), irrespective of housing condition during development or drug treatment. Furthermore, during both familiarisation and choice NOR trials, total object exploration was greater in the isolated groups but unaffected by drug treatment (Table 5). Thus, the improvement in NOR produced by S18841 in isolation-reared rats was not due to increased object attention during acquisition but a preferential improvement in visual recognition memory. 
Table 4 Object exploration during familiarisation and choice novel object recognition trials accompanying Figs. 3 and 4. As detailed in Table 2 legend, object exploration times (s) in the familiarisation and choice trials during the novel object recognition task shown as mean (SEM). In descending order, the groups show (1) the dose-response to systemic administration of the glycine site partial agonist, S18841 alone, (2) S18841 combined with administration of either the NMDA receptor antagonist CPP or the glycine site antagonist L701,324, or S18841 given by discrete microinjection into either the (3) medial prefrontal cortex
(PFC) or (4) the striatum. None of the drugs had any effect on either the total object exploration or distribution of object exploration during the familiarisation trial in any of the studies (all $P>0.05$ ). Treatment with CPP/ L 701,324 significantly reduced total familiarisation trial exploration $(P<0.05)$, and in that study, there was also an effect of S18841 treatment $(P<0.05) . * P<0.05, * * P<0.01, * * * P<0.001$ significantly different from vehicle/vehicle group at that time point; ${ }^{+} P<0.05$ significantly different from S18841/vehicle group at that time point, Fisher LSD post hoc. PFC, prefrontal cortex

\begin{tabular}{|c|c|c|c|c|c|}
\hline \multirow[t]{2}{*}{ Dose of S18841 } & & \multicolumn{3}{|c|}{ Familiarisation trial } & \multirow{2}{*}{$\begin{array}{l}\text { Choice trial } \\
\text { Total exploration (s) }\end{array}$} \\
\hline & & Front object (s) & Back object (s) & Total exploration (s) & \\
\hline Vehicle & $(n=11)$ & $8.9(1.4)$ & $8.5(1.1)$ & $17.4(2.4)$ & $13.3(2.7)$ \\
\hline $0.63 \mathrm{mg} / \mathrm{kg}$ & $(n=11)$ & $7.8(1.6)$ & $7.8(1.3)$ & $15.6(2.6)$ & $13.8(1.3)$ \\
\hline $2.5 \mathrm{mg} / \mathrm{kg}$ & $(n=11)$ & $6.6(1.4)$ & $7.0(1.7)$ & $13.6(2.9)$ & $12.5(2.1)$ \\
\hline $10 \mathrm{mg} / \mathrm{kg}$ & $(n=11)$ & $5.8(0.9)$ & $6.2(0.8)$ & $12.0(1.6)$ & $12.2(1.3)$ \\
\hline Vehicle/Vehicle & $(n=12)$ & $9.4(0.8)$ & $9.5(1.0)$ & $18.9(1.6)$ & $13.6(1.6)$ \\
\hline S18841 ${ }^{\mathrm{a}} /$ Vehicle & $(n=12)$ & $7.8(0.9)$ & $6.8(0.7)$ & $14.7(1.5)^{*}$ & $10.5(1.4)$ \\
\hline $\mathrm{S} 18841^{\mathrm{a}} / \mathrm{CPP}^{\mathrm{b}}$ & $(n=12)$ & $5.8(0.9)$ & $4.8(0.6)$ & $10.7(1.2)^{* *}$ & $8.3(1.4)$ \\
\hline $\mathrm{S} 18841^{\mathrm{a}} / \mathrm{L} 701324^{\mathrm{a}}$ & $(n=12)$ & $4.5(0.9)$ & $5.4(0.7)$ & $9.9(1.3)^{* * *+}$ & $6.6(1.3)$ \\
\hline Vehicle, PFC & $(n=16)$ & $13.5(1.6)$ & $13.1(1.9)$ & $26.5(3.0)$ & $23.2(1.2)$ \\
\hline $2.5 \mu \mathrm{g} / \mathrm{side}$ & $(n=8)$ & $13.3(1.2)$ & $13.9(2.2)$ & $27.2(3.0)$ & $19.5(3.0)$ \\
\hline $10 \mu \mathrm{g} / \mathrm{side}$ & $(n=8)$ & $12.5(1.7)$ & $12.9(1.7)$ & $25.3(3.2)$ & $21.4(2.8)$ \\
\hline Vehicle, striatum & $(n=8)$ & $18.2(3.2)$ & $20.4(3.7)$ & $38.5(6.6)$ & $21.6(2.1)$ \\
\hline $10 \mu \mathrm{g} / \mathrm{side}$ & $(n=8)$ & $17.8(1.4)$ & $17.8(1.8)$ & $35.6(2.9)$ & $21.6(1.3)$ \\
\hline
\end{tabular}

\section{Partial Reversal of CFR Deficits in Isolation-Reared Rats by $\mathrm{S} 18841$}

As reported previously, social isolation from weaning induces deficits in contextual and conditioned associative learning in the CFR task (Fig. $5 \mathrm{f}$ and g) which is thought to have translational relevance to negative valence systems in man. Neither isolation housing nor S18841 treatment altered the latency of rats to cross from the more aversive light to the dark side (data not shown) during conditioning, indicating that alterations in CFR were not confounded by changes in anxiety or locomotor activity. However, freezing after each shock during conditioning was significantly lower in isolates than group-housed rats (Fig. 5f, housing; $F_{(1,45)}=1.57, P<0.001$ ) but increased with each conditioning shock, as in group-housed controls, and S18841 had no effect. Vehicle-treated isolated rats froze for significantly less time than vehicle-treated group-housed littermates $(P<0.01)$ when placed back in the conditioning context $24 \mathrm{~h}$ later (Fig. $5 \mathrm{~g}$ ). ANOVA showed a main effect of housing $\left(F_{(1,45)}=20.09, P\right.$ $<0.001)$ and $\mathrm{S} 18841\left(F_{(2,45)}=7.77, P<0.01\right)$, such that isolates administered the highest dose of S18841 froze significantly more $(P<0.01)$ than vehicle isolates and S18841 restored freezing time in isolates to a level comparable to vehicle group-housed rats. In contrast, freezing time was equivalent in all groups when rats were reintroduced to the context at $48 \mathrm{~h}$ post-conditioning, suggesting that extinction was unaltered by housing condition or S18841. However, presentation of the CS $48 \mathrm{~h}$ after conditioning increased freezing duration in grouphoused more than in isolated rats (Fig. $5 \mathrm{~g}, F_{(1,45)}=$ 17.45, $P<0.001)$, but this was not reversed by $\mathrm{S} 18841$.

\section{Discussion}

Overall, the current study is the first comprehensive comparison of the glycine reuptake inhibitors, sarcosine and ORG24598, the agonists, glycine and D-serine and the partial agonists, S18841 and D-cycloserine on PFC microdialysate amino acid and amine levels and cognitive paradigms in normal rats and a neurodevelopmental model for schizophrenia. Both glycine and GlyT1 inhibitors specifically elevated PFC glycine, while D-serine, and to a lesser extent D-cycloserine, elevated D-serine levels, whereas S18841 had no effect on either amino acid (Table 2). All drugs dose-dependently prevented scopolamine-induced impairment of social recognition in adult rats and over similar dose-ranges attenuated a timedelay-induced reduction of NOR (Table 2). Reversal of NOR deficits by systemic S18841 was prevented by the NMDA receptor antagonist, CPP, and the glycine modulatory site antagonist, L701,324, and the effect of S18841 on NOR replicated by microinjection into the PFC. S18841 also reversed the deficit in NOR and impairment 
a

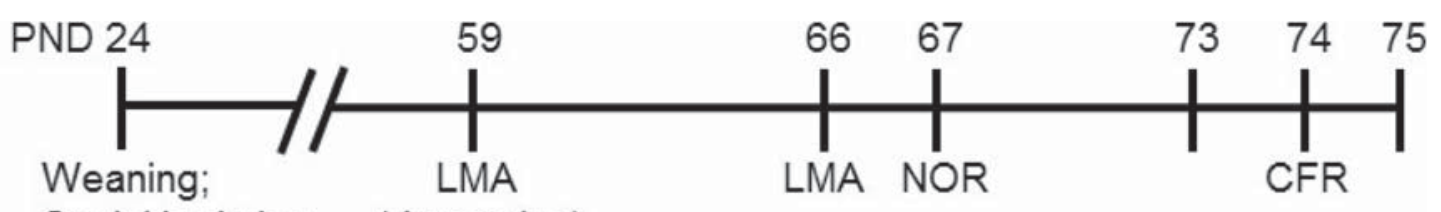

Social Isolation (drug naive)

b

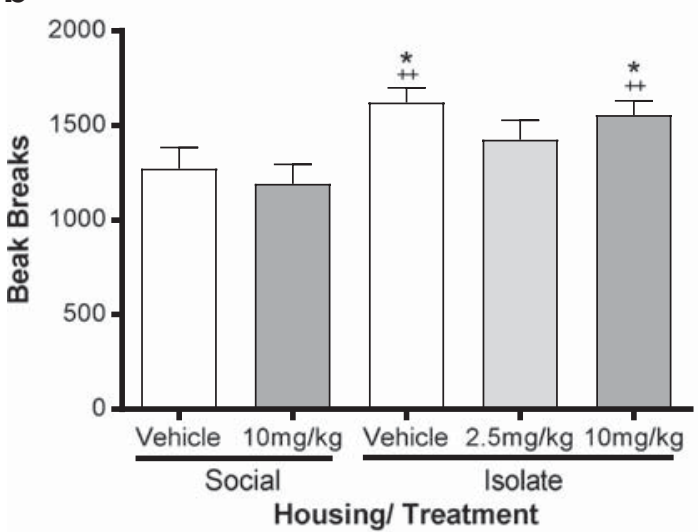

C

d
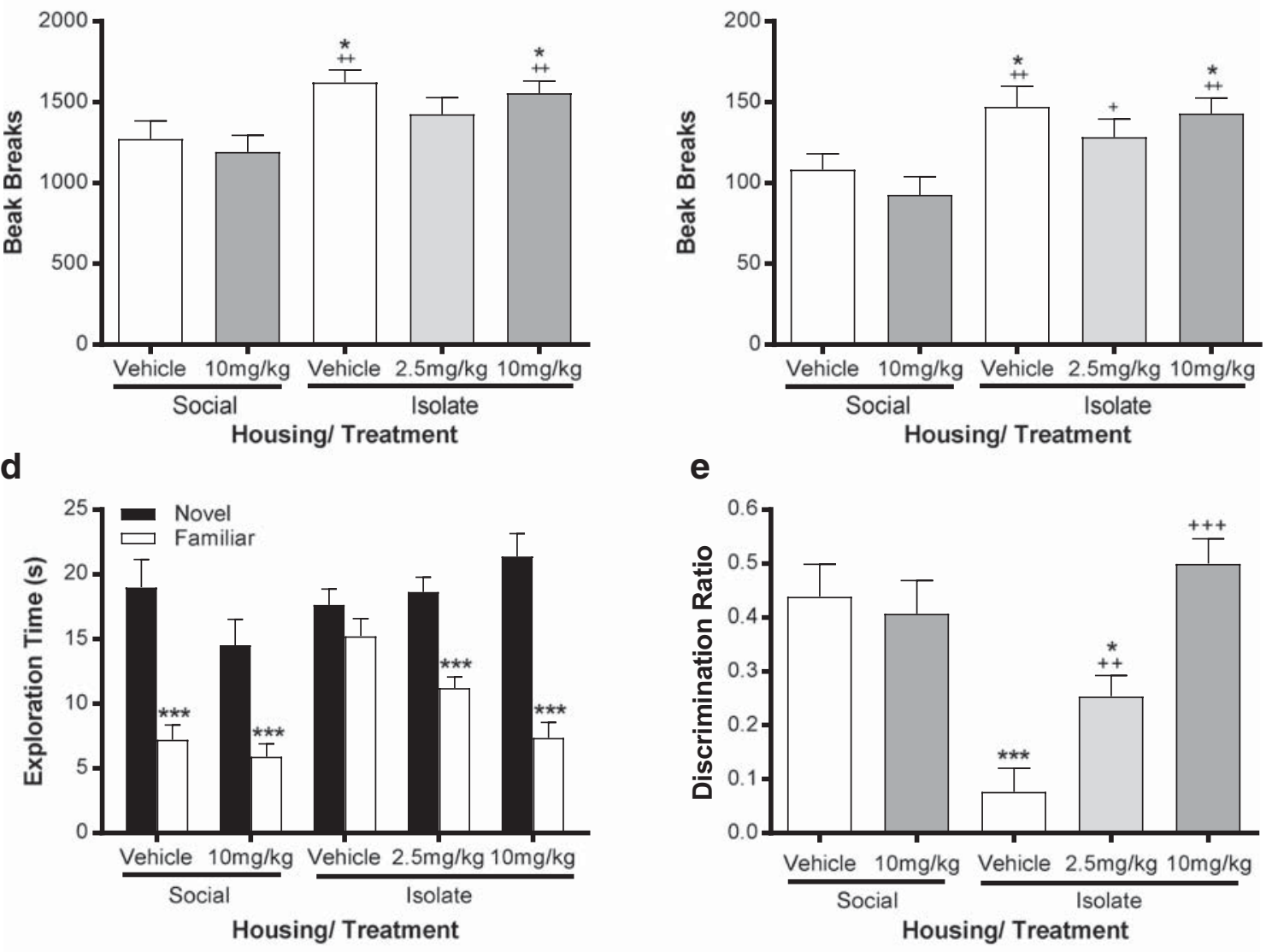

e

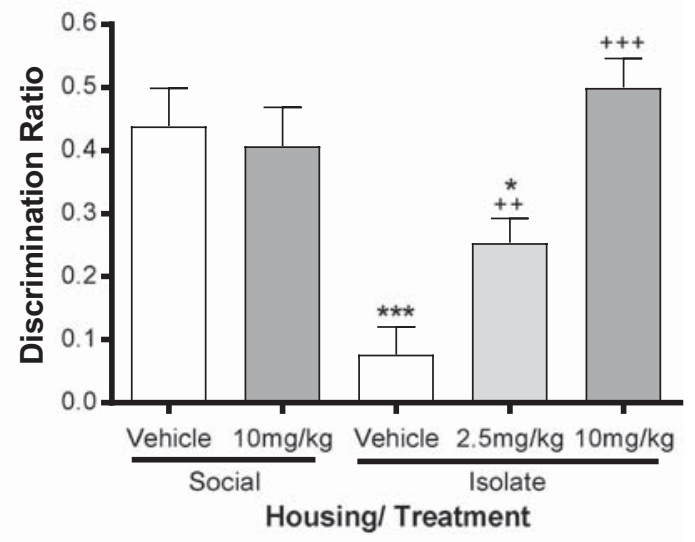

f
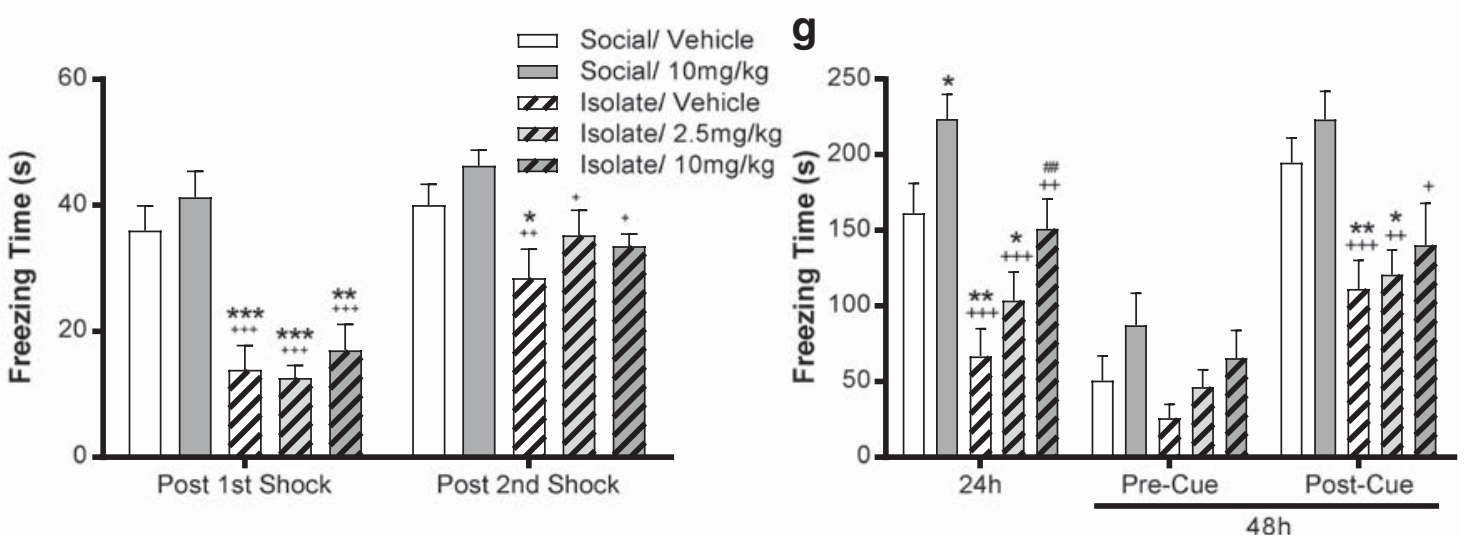

in contextual freezing in a conditioned associative learning task in rats reared in social isolation from weaning (a neurodevelopmental model for schizophrenia). The potential relevance of these findings to cognitive impairments seen in schizophrenia is discussed in detail below.

\section{Modulation of Extracellular Amino Acids Levels of in PFC}

Consistent with extracellular glycine being tightly regulated by GlyT1, and previous work with GlyT1 inhibitors in striatal 
Fig. 5 a Time course protocol for sequential assessment of locomotor activity (LMA), novel object recognition (NOR) and conditioned freezing in rats placed in individual cages (social isolation) or group-housed (littermate controls) from weaning on post natal day 24. Effect of the partial glycine agonist, S18841, on $\mathbf{b}$ locomotor activity and $\mathbf{c}$ number of rears observed over $1 \mathrm{~h}$ in a novel arena, d novel and familiar object exploration time (s) and $\mathbf{e}$ the derived discrimination ratio (novel object exploration-familiar object exploration/total object exploration) during the second choice trial of novel object recognition. Also in the conditioned freezing task, the total freezing time (s) f after the first two of three foot shocks during conditioning and $\mathbf{g}$ upon reintroduction into the chamber $24 \mathrm{~h}$ after conditioning and again $48 \mathrm{~h}$ after conditioning both before (Pre-Cue) and after presentation of the cue alone (Post-Cue), as indicated. Rats were either group-housed (Social) or single housed (Isolate) from weaning on post-natal day 24 . S18841 (2.5 or $10 \mathrm{mg} / \mathrm{kg} \mathrm{s.c.}$ ) or vehicle $(1 \mathrm{ml} / \mathrm{kg}$ ) was injected $30 \mathrm{~min}$ prior to $\mathbf{b}$, $\mathbf{c}$ being placed in the arena for $1 \mathrm{~h}, \mathbf{d}, \mathbf{e}$ before the familiarisation trial and $\mathbf{f}, \mathbf{g}$ before receiving foot shock conditioning in the associative learning paradigm. Data expressed as mean \pm SEM, $n=10$ per group. In $\mathbf{b}$, RM-ANOVA showed a significant main effect of housing $(P<0.001)$ but not drug treatment $(P=0.283)$. ${ }^{*} P$ $<0.05$ from social/vehicle rats; ${ }^{++} P<0.01$ from social $/ 10 \mathrm{mg} / \mathrm{kg} \mathrm{S} 18841$, Fishers LSD. c RM-ANOVA revealed a significant main effect of housing $(P<0.001)$ but not drug treatment $(P=0.317)$. $* P<0.05$ from social/ vehicle rats; ${ }^{+} P<0.05,{ }^{++} P<0.01$ from social $/ 10 \mathrm{mg} / \mathrm{kg} \mathrm{S} 18841$, Fishers LSD. d RM-ANOVA showed a significant object $\times$ S18841 treatment $(P$ $<0.05)$ and object $\times \mathrm{S} 18841$ treatment $\times$ housing $(P<0.001)$ interaction, $* * * P<0.001$ from novel object in same treatment group, Bonferroni post hoc. e ANOVA revealed a significant main effect of housing $(P<0.05)$ and $\mathrm{S} 18841$ treatment $(P<0.001)$ and a significant housing $\times \mathrm{S} 18841$ interaction $(P<0.001), * P<0.05, * * * P<0.001$ from social/vehicle. $\mathbf{f}$ RM-ANOVA indicated a significant conditioning $\times$ housing interaction $(P<0.05)$ and a main effect of housing $(P<0.001), * P<0.05$, ***P $<0.001$ significantly different from social $/$ vehicle at that time point; ${ }^{+} P$ $<0.05,{ }^{++} P<0.01,{ }^{+++} P<0.001$ from social $/ 10 \mathrm{mg} / \mathrm{kg} \mathrm{S} 18841$, Fisher LSD post hoc. $g$ At $24 \mathrm{~h}$ post-conditioning ANOVA indicated a significant main effect of housing $(P<0.001)$ and $\mathrm{S} 18841$ treatment $(P<0.05)$. At $48 \mathrm{~h}$, there was no main effect of housing or S18841 treatment pre-cue but there was a main effect of housing post cue $(P<0.001), * P<0.05$, $* * P<0.01$ from social/vehicle; ${ }^{+} P<0.05,{ }^{++} P<0.01,{ }^{+++} P<0.001$ from social $/ 10 \mathrm{mg} / \mathrm{kg} \mathrm{S} 18841,{ }^{\# \#} P<0.01$ from isolate/vehicle Fisher LSD post hoc

microdialysates, sarcosine and ORG24598 elevated PFC glycine [30, 51, 67-70] although striatal elevations may be more marked than those in the PFC [37, 70]. Notably, doses of bitopertin achieving high GlyT1 occupancy in humans also elevated CSF glycine suggesting translational pertinence of rat microdialysis studies [71, 72]. Both ORG24598 and sarcosine specifically elevated glycine, without effecting D-serine, other amino acids or acetylcholine, which could contribute to their cognitive effects (Table 1). The only other change was a modest increase in dopamine by sarcosine (Table 1).

These observations are important since, to our knowledge, this is the first comprehensive neurochemical characterisation of sarcosine, despite its extensive use as a specific "GlyT1 inhibitor" and an adjunctive agent in schizophrenia patients [12, 73, 74]. Lack of change in 5-HT is important given concerns about a potential interaction with serotonergic transmission at a clinical dose of $2 \mathrm{~g} \mathrm{[75]}$ and a transient elevation of rat PFC 5-HT with an extremely high dose ( $2 \mathrm{~g} / \mathrm{kg}$ p.o.) of sarcosine [76].

Glycine also elevated dialysate dopamine (and norepinephrine but not 5-HT), the rise being more pronounced than with GlyT1 inhibitors, and completely selective (Table 1) versus other amino acids [51]. It is unclear how glycine elevates dopamine and norepinephrine levels, but this effect is unlikely to involve NMDA receptor recruitment as other glycine site agonists had no effect. One possibility might be a modification of GABA interneuron input to dopaminergic pathways [77]. Increased PFC dopamine release may be advantageous to elevate cognitive and negative symptoms in man [37].

In a mirror image of glycine, D-serine markedly elevated D-serine without affecting glycine [51] or other amines including 5-HT, suggesting that the slight increase in 5-HT in a previous dialysis study [76] resulted from an unselective effect of the much higher dose $(2 \mathrm{~g} / \mathrm{kg})$ used. Extracellular cortical D-serine levels are dynamically regulated by alanine-serine-cysteine transporters and reflect both neuronal and glial origin [37, 78, 79].

A previous microdialysis study reported that systemic Dcycloserine elevated PFC D-serine levels [80], both in wildtype and serine racemase knockout mice, so it is unlikely to reflect altered synthesis [81]. We confirm herein that Dcycloserine modestly increased PFC dialysis D-serine, again without affecting other amino acids or neurotransmitters (Table 1). As proposed by Horio et al. [81], metabolism of Dcycloserine to D-serine may account for this rise rather than any effect on the glycine site, since neither S18841 (which cannot be transformed into D-serine) nor the antagonist, L701,324, affected D-serine. Moreover, D-serine was unaltered by the other partial agonists. Finally, S18841 exerted no influence at all on extracellular levels of any amino acid (including aspartate and taurine, not shown) or neurotransmitter encouraging us to focus on this pharmacological tool for further studies.

Importantly, demonstration of the highly selective action of sarcosine, ORG24598, glycine (on glycine) and D-serine and D-cycloserine (on D-serine) at doses relevant to those used as adjuncts in schizophrenia clinical trials $[10,17,26]$ provides evidence of the likely common PFC neurochemical mechanisms involved in their actions.

\section{Reversal of Scopolamine-Impaired Social Recognition and Time Delay Deficit in Novel Object Recognition}

Scopolamine reproducibly impaired social recognition memory, and this was reversed (in a dose-related manner) by at least two doses of the glycine modulatory site agonists glycine and D-serine, partial agonists D-cycloserine and S18841, and the GlyT1 inhibitors sarcosine and ORG24598. Although the pathological relevance of scopolamine as a cognitive disruptor can be questioned, it has been used as a translational tool to investigate GlyT1 inhibitors in primates and man [82, 83]. 
Table 5 Object exploration during the familiarisation and choice trials in the novel object recognition task in rat littermates reared from weaning either as a group or in social isolation accompanying Fig. 5 in the manuscript. As detailed in Table 2 legend, object exploration times (s) in the familiarisation and choice trials (separated by a $2 \mathrm{~h}$ interval) during the novel object discrimination task shown as mean (SEM), $n=10$ per group. Rats were injected with either S18841 (2.5 or $10 \mathrm{mg} / \mathrm{kg}$ ) or vehicle $(1 \mathrm{ml} / \mathrm{kg})$ s.c. $30 \mathrm{~min}$ prior to start of task. During the familiarisation trial, although there was no significant difference between the exploration of the front and back object, there was a significant location $\times$ housing $(P<0.01)$ and location $\times \mathrm{S} 18841$ treatment $(P<0.05)$ interaction. During both the familiarisation and choice trials, ANOVA showed a main effect of housing $(P<0.05$ and $P<0.01$, respectively). However, post hoc analysis revealed that the only significant differences were between the group-housed (social) rats administered S18841 and the isolationreared rats, ${ }^{+} P<0.05,{ }^{++} P<0.01$ significantly different from social/ $10 \mathrm{mg} / \mathrm{kg} \mathrm{S18841}$ group during that trial, Fisher LSD post hoc

\begin{tabular}{|c|c|c|c|c|c|}
\hline \multirow[t]{2}{*}{ Housing } & \multirow[t]{2}{*}{ Drug } & \multicolumn{3}{|c|}{ Familiarisation trial } & \multirow{2}{*}{$\begin{array}{l}\text { Choice trial } \\
\text { Total exploration (s) }\end{array}$} \\
\hline & & Front object (s) & Back object (s) & Total exploration (s) & \\
\hline Social & Vehicle & $15.9(1.5)$ & $14.8(2.1)$ & $31.2(3.5)$ & $28.7(1.7)$ \\
\hline Social & $10 \mathrm{mg} / \mathrm{kg}$ & $12.3(2.0)$ & $11.3(2.1)$ & $25.8(3.0)$ & $22.4(2.3)$ \\
\hline Isolate & Vehicle & $13.7(1.1)$ & $19.5(1.4)$ & $33.2(1.4)^{+}$ & $32.9(2.2)^{++}$ \\
\hline Isolate & $2.5 \mathrm{mg} / \mathrm{kg}$ & $15.4(1.6)$ & $14.8(1.5)$ & $30.2(2.6)$ & $29.8(1.7)^{++}$ \\
\hline Isolate & $10 \mathrm{mg} / \mathrm{kg}$ & $14.1(1.9)$ & $18.8(1.8)$ & $32.9(3.5)^{+}$ & $28.7(2.4)^{+}$ \\
\hline
\end{tabular}

All compounds also reduced a time-delay impairment of NOR that was dose-related for glycine, D-serine sarcosine and S18841. These pro-cognitive effects are consistent with previous studies. D-serine and NFPS improved performance in time-delay impairment of social recognition [84]. Spontaneous NOR in mice and place recognition in rats and mice was enhanced by D-cycloserine [85-87]. Supporting the current data that sarcosine and ORG24598 attenuated natural forgetting in NOR performance, glycine reuptake inhibitors NFPS [84] TASP0315003 [88] and sarcosine all improved NOR and NMDA antagonist-impaired social recognition.

\section{Involvement of the NMDA Receptor and PFC in S18841-Induced NOR Improvement}

In this study, reversal of the time-delay-induced impairment of NOR by acute S18841 was prevented by pre-treatment with the glycine site antagonist, L701,324, and the NDMA receptor antagonist, CPP, suggesting that NMDA receptor activation is required for the action of S18841. Consistent with this proposal, D-serine reversed the NOR impairment produced by the NMDA antagonists, MK-801 [87, 89] or PCP [87, 90]. In primates, D-cycloserine improved performance in a variable delayed response task in the MPTP model of Parkinsonism [91] and reversed impairments in a visual delay nonmatching-to-sample task caused by glycine site or NMDA receptor antagonism [92]. Similarly, the partial glycine site agonist, GLYX-13 (Rapastinel), restored a PCP-induced NOR impairment [93]. Both sarcosine and the glycine reuptake inhibitor (R)-(N-[3-(4'-fluorophenyl)-3-(4'phenylphenoxy)propyl]) reversed an NMDA antagonistinduced impairment of NOR in rats and mice $[89,90]$ congruent with the proposal that glycine-induced enhancement of NMDA receptor function mediates the reported procognitive effects.
Bilateral microinjection of S18841 into the PFC (but not the striatum) dose-relatedly reversed intertrial delay-impaired NOR. However, the role of the PFC in NOR is complex, such that dopamine $\mathrm{D}_{2}$ and $\mathrm{D}_{3}$ receptor drugs have opposite effects on performance when injected into the PFC [54, 94]. Furthermore, D-cycloserine injection into the prelimbic cortex reversed scopolamine-induced amnesia in two olfactory (odour discrimination and food preference) tasks [95], suggesting that the cortex may be a target for the observed reversal of muscarinic attenuation of social recognition reported herein. Of note, serine racemase knockout (SR-/-) mice develop neurons with reduced complexity, length and spine density of apical dendrites in the medial PFC and show impaired NOR [96].

\section{Restoration of Cognitive Performance but Not of Locomotor Activity by S18841 in Isolation-Reared Rats}

Rats reared in isolation took longer to habituate to a novel environment, but this hyperactivity, thought to reflect a mesolimbic hyperdopaminergic state analogous to that in psychosis [97], was unaffected by S18841. Current antipsychotics reverse the isolation-induced hyperactivity, at least in part, through antagonism of dopamine $\mathrm{D}_{2}$ receptors $[46,49,98]$. Glycine site ligands do not possess $\mathrm{D}_{2}$ affinity but may exert antipsychotic properties by a contrasting mechanism or enhance the clinical actions of antipsychotic drugs (although they have never actually been tested alone in patients).

Consistent with previous studies [44-47], isolates showed a marked NOR deficit that was reversed by S18841, suggesting that glycine site agonists can reduce premature forgetting in this neurodevelopmental model of schizophrenia. Only one study has examined the effect of a glycine modulatory compound in isolation-reared rats. D-Cycloserine reversed a 
deficit in retention in a visual discrimination task [99]. In the present CFR task, social isolation reduced contextual freezing $24 \mathrm{~h}$ post-conditioning and when the cue was presented $48 \mathrm{~h}$ post-training, consistent with impaired associative memory reported previously $[45,46,48]$. S18841 given prior to conditioning attenuated the isolation-induced reduction in contextual freezing. Interestingly, the contextual memory phase of this task in rats is NMDA receptor dependent, being attenuated by MK-801 [66], consistent with the current hypothesised mechanism of S18841.

\section{General Discussion and Broader-Clinical Relevance of the Present Observations}

As a note of caution both social recognition and NOR tasks rely on spontaneous preference for novelty and their predictive validity to cognitive impairment in schizophrenia requires further confirmation $[39,100,101]$. For instance, drugs with different pharmacological mechanisms, such as $\alpha 7$-nicotinic agonists and $5-\mathrm{HT}_{6}$ receptor antagonists produced much smaller improvements in cognition in schizophrenia clinical trials than would have been predicted from preclinical data, even in studies using disease models rather than normal animals. Nonetheless, in our hands, selective dopamine $\mathrm{D}_{2}$ receptor antagonists impair social novelty discrimination and NOR [54] consistent with the lack of effect or worsening of cognition seen with current antipsychotics in patients with schizophrenia, while the dopamine partial agonist cariprazine reversed the isolation-rearing induced impairment in NOR [49].

Taken together, this study provides extensive, consistent complimentary and neurochemical evidence that pharmacological modulation of glycine site activity on NMDA receptors can improve cognitive dysfunction in rats, but similar robust positive observations have not been reported in schizophrenia trials using glycine site agonists [17, 26]. Poor translation may result from desensitisation of the glycine site as seen with repeated D-cycloserine [102], producing NMDA receptor internalisation [103] which might not occur with acute administration used in most animal studies. Second, the glycine full and partial agonists appear to have differential affinity for the different NMDA receptor subunit compositions found at pre- and post-synaptic sites in the cortex [104] that could affect their relative clinical effectiveness. Thirdly, the ability of glycine site agonists to facilitate symptom improvement may be impeded by antipsychotics with muscarinic antagonism, such as clozapine and other atypicals, by opposing any pro-cognitive actions [94]. Interestingly, D-serine, D-cycloserine and sodium benzoate all improve haloperidolinduced bradykinesia in the rat by elevating nigrostriatal dopamine release, suggesting that they may also reduce antipsychotic-induced extrapyramidal side effects [105]. Furthermore, they might be useful in the prodromal phase to alleviate pre-diagnostic symptoms and, by improving social cognition and social integration, decrease risk of transition to psychosis [27-29, 37].

The present observations provide a framework to examine other agents, including novel glycine site agonists, like Rapastinel [93] and NSX-2925 [14], the uptake inhibitors TASP0315003 [88] and bitopertin [35, 36], D-amino acid oxidases inhibitors like sodium benzoate $[22,106]$, and inhibitors of kynurenine aminotransferase II all of which modify PFC glutamatergic signalling [107, 108]. Furthermore, it would be interesting to study agents acting at the neuronal alanine-serinecysteine-1 transporter which is implicated in the control of extracellular D-serine and glycine [8, 109]. Finally, one might compare the actions of BMS-466442, which suppresses D-serine uptake [110], with those of LuAE00527 which prevents D-serine release [79].

Although most research focusses on these agents enhancing cognition in psychiatric disorders [5, 111], current findings are pertinent to disorders, like Alzheimer's disease [112,113], where plasma D-amino acid oxidase levels correlate with cognitive decline [114] but other work suggests that elevated brain D-serine occurs in Alzheimer's [112]. Furthermore, akin to the fast antidepressant actions of ketamine, glycine site partial agonists like Rapastinel may exert antidepressant effects via enhanced mTOR and BDNF signalling $[1,3]$. Intriguingly, the major metabolites of ketamine are D-serine racemase inhibitors [1-3], providing a direct link to the present work. In addition, D-cycloserine and other glycine site ligands may improve social cognition in ASDs and genetically related Rett syndrome $[115,116]$. Other indications under consideration include drug abuse [117], amyotrophic lateral sclerosis [22], chronic pain [118] and facilitation of psychosocial-cognitive behavioural therapies for anxiety disorders [119].

Acknowledgements We thank Clare Spicer for technical assistance. Studies were designed by KCFF and MJM. Experimental work was undertaken at the University of Nottingham by DJGW and KCFF and at Servier by AG, RB, DS, AD and J-MR. The first draft of the manuscript was produced by DJGW, KCFF and MJM, and all authors contributed to production of the final version.

\section{Compliance with Ethical Standards}

Ethical Approval All procedures performed in studies involving animals were performed in accordance with the ethical standards of the University of Nottinhgam, the Animals (Scientific Procedures) Act, 1986 and ARRIVE guidelines and with approval of University of Nottingham Local Ethical Committee (behavior) or EU guidelines (microdialysis).

Conflict of Interest We declare that, except for income received from their primary employer, no financial support or compensation has been received from any individual or corporate entity over the past 3 years for research or professional service, and there are no personal financial holdings that could be perceived as constituting a 
potential conflict of interest. The contribution to this work made by DJGW and KCFF was financially supported by Servier. MJM, AG, $\mathrm{RB}, \mathrm{DS}, \mathrm{AD}$ and J-MR are employed by Servier.

Open Access This article is licensed under a Creative Commons Attribution 4.0 International License, which permits use, sharing, adaptation, distribution and reproduction in any medium or format, as long as you give appropriate credit to the original author(s) and the source, provide a link to the Creative Commons licence, and indicate if changes were made. The images or other third party material in this article are included in the article's Creative Commons licence, unless indicated otherwise in a credit line to the material. If material is not included in the article's Creative Commons licence and your intended use is not permitted by statutory regulation or exceeds the permitted use, you will need to obtain permission directly from the copyright holder. To view a copy of this licence, visit http://creativecommons.org/licenses/by/4.0/.

\section{References}

1. Zanos P, Moaddel R, Morris PJ, Georgiou P, Fischell J, Elmer GI, Alkondon M, Yuan P et al (2016) NMDAR inhibitionindependent antidepressant actions of ketamine metabolites. Nature 533(7604):481-486. https://doi.org/10.1038/nature17998

2. Yao N, Skiteva O, Zhang X, Svenningsson P, Chergui K (2018) Ketamine and its metabolite (2R,6R)-hydroxynorketamine induce lasting alterations in glutamatergic synaptic plasticity in the mesolimbic circuit. Mol Psychiatry 23(10):2066-2077. https:// doi.org/10.1038/mp.2017.239

3. Cavalleri L, Merlo Pich E, Millan MJ, Chiamulera C, Kunath T, Spano PF, Collo G (2018) Ketamine enhances structural plasticity in mouse mesencephalic and human iPSC-derived dopaminergic neurons via AMPAR-driven BDNF and mTOR signaling. Mol Psychiatry 23(4):812-823. https://doi.org/10.1038/mp.2017.241

4. Moghaddam B, Javitt D (2012) From revolution to evolution: The glutamate hypothesis of schizophrenia and its implication for treatment. Neuropsychopharmacology 37(1):4-15. https://doi. org/10.1038/npp.2011.181

5. Collingridge GL, Volianskis A, Bannister N, France G, Hanna L, Mercier M, Tidball P, Fang G et al (2013) The NMDA receptor as a target for cognitive enhancement. Neuropharmacology 64:1326. https://doi.org/10.1016/j.neuropharm.2012.06.051

6. Fossat P, Turpin FR, Sacchi S, Dulong J, Shi T, Rivet JM, Sweedler JV, Pollegioni L et al (2012) Glial D-serine gates NMDA receptors at excitatory synapses in prefrontal cortex. Cereb Cortex 22(3):595-606. https://doi.org/10.1093/cercor/ bhr130

7. Lench AM, Massey PV, Pollegioni L, Woodhall GL, Jones RS (2014) Astroglial d-serine is the endogenous co-agonist at the presynaptic NMDA receptor in rat entorhinal cortex. Neuropharmacology 83:118-127. https://doi.org/10.1016/j. neuropharm.2014.04.004

8. Rosenberg D, Artoul S, Segal AC, Kolodney G, Radzishevsky I, Dikopoltsev E, Foltyn VN, Inoue R et al (2013) Neuronal D-serine and glycine release via the Asc-1 transporter regulates NMDA receptor-dependent synaptic activity. J Neurosci 33(8):35333544. https://doi.org/10.1523/jneurosci.3836-12.2013

9. Ju P, Cui D (2016) The involvement of N-methyl-D-aspartate receptor (NMDAR) subunit NR1 in the pathophysiology of schizophrenia. Acta Biochim Biophys Sin Shanghai 48(3):209219. https://doi.org/10.1093/abbs/gmv135

10. Balu DT (2016) The NMDA receptor and schizophrenia: From pathophysiology to treatment. Adv Pharmacol (San Diego, Calif) 76:351-382. https://doi.org/10.1016/bs.apha.2016.01.006
11. Harvey RJ, Yee BK (2013) Glycine transporters as novel therapeutic targets in schizophrenia, alcohol dependence and pain. Nat Rev Drug Discov 12(11):866-885. https://doi.org/10.1038/ $\operatorname{nrd} 3893$

12. Lin CY, Liang SY, Chang YC, Ting SY, Kao CL, Wu YH, Tsai GE, Lane HY (2017) Adjunctive sarcosine plus benzoate improved cognitive function in chronic schizophrenia patients with constant clinical symptoms: A randomised, double-blind, placebocontrolled trial. World J Biol Psychiatry 18(5):357-368. https:// doi.org/10.3109/15622975.2015.1117654

13. Burgdorf J, Zhang XL, Nicholson KL, Balster RL, Leander JD, Stanton PK, Gross AL, Kroes RA et al (2013) GLYX-13, a NMDA receptor glycine-site functional partial agonist, induces antidepressant-like effects without ketamine-like side effects. Neuropsychopharmacology 38(5):729-742. https://doi.org/10. 1038/npp.2012.246

14. Khan MA, Houck DR, Gross AL, Zhang XL, Cearley C, Madsen TM, Kroes RA, Stanton PK et al (2018) NYX-2925 is a novel NMDA receptor-specific spirocyclic-beta-lactam that modulates synaptic plasticity processes associated with learning and memory. Int J Neuropsychopharmacol 21(3):242-254. https://doi.org/10. 1093/ijnp/pyx096

15. Cordi A, Lacoste JM, Audinot V, Millan M (1999) Design, synthesis and structure-activity relationships of novel strychnineinsensitive glycine receptor ligands. Bioorg Med Chem Lett 9(10):1409-1414

16. Balu DT, Coyle JT (2015) The NMDA receptor 'glycine modulatory site' in schizophrenia: D-serine, glycine, and beyond. Curr Opin Pharmacol 20:109-115. https://doi.org/10.1016/j.coph. 2014.12.004

17. Goff DC (2017) D-cycloserine in schizophrenia: New strategies for improving clinical outcomes by enhancing plasticity. Curr Neuropharmacol 15(1):21-34

18. Schwarcz R, Rassoulpour A, Wu HQ, Medoff D, Tamminga CA, Roberts RC (2001) Increased cortical kynurenate content in schizophrenia. Biol Psychiatry 50(7):521-530

19. Bendikov I, Nadri C, Amar S, Panizzutti R, De Miranda J, Wolosker H, Agam G (2007) A CSF and postmortem brain study of D-serine metabolic parameters in schizophrenia. Schizophr Res 90(1-3):41-51. https://doi.org/10.1016/j.schres.2006.10.010

20. Brouwer A, Luykx JJ, van Boxmeer L, Bakker SC, Kahn RS (2013) NMDA-receptor coagonists in serum, plasma, and cerebrospinal fluid of schizophrenia patients: A meta-analysis of casecontrol studies. Neurosci Biobehav Rev 37(8):1587-1596. https://doi.org/10.1016/j.neubiorev.2013.06.007

21. Neeman G, Blanaru M, Bloch B, Kremer I, Ermilov M, Javitt DC, Heresco-Levy U (2005) Relation of plasma glycine, serine, and homocysteine levels to schizophrenia symptoms and medication type. Am J Psychiatry 162(9):1738-1740. https://doi.org/10.1176/ appi.ajp.162.9.1738

22. Molla G (2017) Competitive inhibitors unveil structure/function relationships in human D-amino acid oxidase. Front Mol Biosci 4: 80. https://doi.org/10.3389/fmolb.2017.00080

23. Santini AC, Pierantoni GM, Gerlini R, Iorio R, Olabinjo Y, Giovane A, Di Domenico M, Sogos C (2014) Glix 13, a new drug acting on glutamatergic pathways in children and animal models of autism spectrum disorders. Biomed Res Int 2014:234295. https://doi.org/10.1155/2014/234295

24. Wu HF, Chen PS, Hsu YT, Lee CW, Wang TF, Chen YJ, Lin HC (2018) D-Cycloserine ameliorates autism-like deficits by removing GluA2-containing AMPA receptors in a valproic acid-induced rat model. Mol Neurobiol 55(6):4811-4824. https://doi.org/10. 1007/s12035-017-0685-1

25. Urbano M, Okwara L, Manser P, Hartmann K, Herndon A, Deutsch SI (2014) A trial of D-cycloserine to treat stereotypies in older adolescents and young adults with autism spectrum 
disorder. Clin Neuropharmacol 37(3):69-72. https://doi.org/10. 1097/WNF.0000000000000033

26. Iwata Y, Nakajima S, Suzuki T, Keefe RS, Plitman E, Chung JK, Caravaggio F, Mimura M et al (2015) Effects of glutamate positive modulators on cognitive deficits in schizophrenia: A systematic review and meta-analysis of double-blind randomized controlled trials. Mol Psychiatry 20(10):1151-1160. https://doi.org/10.1038/ mp.2015.68

27. Devoe DJ, Peterson A, Addington J (2018) Negative symptom interventions in youth at risk of psychosis: A systematic review and network meta-analysis. Schizophr Bull 44(4):807-823. https://doi.org/10.1093/schbul/sbx139

28. Millan MJ, Andrieux A, Bartzokis G, Cadenhead K, Dazzan P, Fusar-Poli P, Gallinat J, Giedd J et al (2016) Altering the course of schizophrenia: Progress and perspectives. Nat Rev Drug Discov 15(7):485-515. https://doi.org/10.1038/nrd.2016.28

29. Woods SW, Walsh BC, Hawkins KA, Miller TJ, Saksa JR, D'Souza DC, Pearlson GD, Javitt DC et al (2013) Glycine treatment of the risk syndrome for psychosis: Report of two pilot studies. Eur Neuropsychopharmacol 23(8):931-940. https://doi. org/10.1016/j.euroneuro.2012.09.008

30. Alberati D, Moreau JL, Lengyel J, Hauser N, Mory R, Borroni E, Pinard E, Knoflach F et al (2012) Glycine reuptake inhibitor RG1678: A pharmacologic characterization of an investigational agent for the treatment of schizophrenia. Neuropharmacology 62(2):1152-1161. https://doi.org/10.1016/j.neuropharm.2011.11. 008

31. Kopec K, Flood DG, Gasior M, McKenna BA, Zuvich E, Schreiber J, Salvino JM, Durkin JT et al (2010) Glycine transporter (GlyT1) inhibitors with reduced residence time increase prepulse inhibition without inducing hyperlocomotion in DBA/2 mice. Biochem Pharmacol 80(9):1407-1417. https://doi.org/10. 1016/j.bcp.2010.07.004

32. Harada K, Nakato K, Yarimizu J, Yamazaki M, Morita M, Takahashi S, Aota M, Saita K et al (2012) A novel glycine transporter-1 (GlyT1) inhibitor, ASP2535 (4-[3-isopropyl-5-(6phenyl-3-pyridyl)-4H-1,2,4-triazol-4-yl]-2,1,3-benzoxadiazol e), improves cognition in animal models of cognitive impairment in schizophrenia and Alzheimer's disease. Eur J Pharmacol 685(13):59-69. https://doi.org/10.1016/j.ejphar.2012.04.013

33. Young JW, Kamenski ME, Higa KK, Light GA, Geyer MA, Zhou X (2015) GlyT-1 inhibition attenuates attentional but not learning or motivational deficits of the Sp4 hypomorphic mouse model relevant to psychiatric disorders. Neuropsychopharmacology 40(12):2715-2726. https://doi.org/10.1038/npp.2015.120

34. Umbricht D, Alberati D, Martin-Facklam M, Borroni E, Youssef EA, Ostland M, Wallace TL, Knoflach F et al (2014) Effect of bitopertin, a glycine reuptake inhibitor, on negative symptoms of schizophrenia: A randomized, double-blind, proof-of-concept study. JAMA Psychiatry 71(6):637-646. https://doi.org/10.1001/ jamapsychiatry.2014.163

35. Singer P, Dubroqua S, Yee BK (2015) Inhibition of glycine transporter 1: The yellow brick road to new schizophrenia therapy? Curr Pharm Design 21(26):3771-3787. https://doi.org/10.2174/ 1381612821666150724100952

36. Bugarski-Kirola D, Iwata N, Sameljak S, Reid C, Blaettler T, Millar L, Marques TR, Garibaldi G et al (2016) Efficacy and safety of adjunctive bitopertin versus placebo in patients with suboptimally controlled symptoms of schizophrenia treated with antipsychotics: Results from three phase 3, randomised, doubleblind, parallel-group, placebo-controlled, multicentre studies in the SearchLyte clinical trial programme. Lancet Psychiatry 3(12):1115-1128. https://doi.org/10.1016/s2215-0366(16)303443

37. Millan MJ, Rivet JM, Gobert A (2016) The frontal cortex as a network hub controlling mood and cognition: Probing its neurochemical substrates for improved therapy of psychiatric and neurological disorders. J Psychopharmacol 30(11):10991128. https://doi.org/10.1177/0269881116672342

38. Young JW, Powell SB, Risbrough V, Marston HM, Geyer MA (2009) Using the MATRICS to guide development of a preclinical cognitive test battery for research in schizophrenia. Pharmacol Ther 122(2):150-202. https://doi.org/10.1016/j.pharmthera.2009. 02.004

39. Millan MJ, Bales KL (2013) Towards improved animal models for evaluating social cognition and its disruption in schizophrenia: The CNTRICS initiative. Neurosci Biobehav Rev 37(9):21662180. https://doi.org/10.1016/j.neubiorev.2013.09.012

40. Fone KC, Porkess MV (2008) Behavioural and neurochemical effects of post-weaning social isolation in rodents-relevance to developmental neuropsychiatric disorders. Neurosci Biobehav Rev 32(6):1087-1102. https://doi.org/10.1016/j.neubiorev.2008. 03.003

41. Jones CA, Watson DJ, Fone KC (2011) Animal models of schizophrenia. Br J Pharmacol 164(4):1162-1194. https://doi.org/10. 1111/j.1476-5381.2011.01386.x

42. Fabricius K, Helboe L, Steiniger-Brach B, Fink-Jensen A, Pakkenberg B (2010) Stereological brain volume changes in post-weaned socially isolated rats. Brain Res 1345:233-239. https://doi.org/10.1016/j.brainres.2010.05.040

43. Schubert MI, Porkess MV, Dashdorj N, Fone KCF, Auer DP (2009) Effects of social isolation rearing on the limbic brain: A combined behavioral and magnetic resonance imaging volumetry study in rats. Neuroscience 159(1):21-30. https://doi.org/10.1016/ j.neuroscience.2008.12.019

44. Gaskin PL, Toledo-Rodriguez M, Alexander SP, Fone KC (2016) Down-regulation of hippocampal genes regulating dopaminergic, GABAergic, and glutamatergic function following combined neonatal phencyclidine and post-weaning social isolation of rats as a neurodevelopmental model for schizophrenia. Int J Neuropsychopharmacol 19(11). https://doi.org/10.1093/ijnp/ pyw062

45. Jones CA, Brown AM, Auer DP, Fone KC (2011) The mGluR2/3 agonist LY379268 reverses post-weaning social isolation-induced recognition memory deficits in the rat. Psychopharmacology 214(1):269-283. https://doi.org/10.1007/s00213-010-1931-7

46. McIntosh AL, Ballard TM, Steward LJ, Moran PM, Fone KC (2013) The atypical antipsychotic risperidone reverses the recognition memory deficits induced by post-weaning social isolation in rats. Psychopharmacology 228(1):31-42. https://doi.org/10.1007/ s00213-013-3011-2

47. Meffre J, Chaumont-Dubel S, la Cour CM, Loiseau F, Watson DJG, Dekeyne A, Seveno M, Rivet J-M et al (2012) 5-HT6 receptor recruitment of mTOR as a mechanism for perturbed cognition in schizophrenia. EMBO Mol Med 4(10):1043-1056. https:// doi.org/10.1002/emmm.201201410

48. Gaskin PL, Alexander SP, Fone KC (2014) Neonatal phencyclidine administration and post-weaning social isolation as a dual-hit model of 'schizophrenia-like' behaviour in the rat. Psychopharmacology 231(12):2533-2545. https://doi.org/10. 1007/s00213-013-3424-y

49. Watson DJG, King MV, Gyertyan I, Kiss B, Adham N, Fone KCF (2016) The dopamine $\mathrm{D}(3)$-preferring $\mathrm{D}(2) / \mathrm{D}(3)$ dopamine receptor partial agonist, cariprazine, reverses behavioural changes in a rat neurodevelopmental model for schizophrenia. Eur Neuropsychopharmacol 26(2):208-224. https://doi.org/10.1016/ j.euroneuro.2015.12.020

50. Paxinos G, Watson C (1998) The rat brain in Stereotaxis coordinates, 4th edition, 4th edn. Academic Press, London

51. Gobert A, Rivet JM, Billiras R, Parsons F, Millan MJ (2011) Simultaneous quantification of D- vs. L-serine, taurine, kynurenate, phosphoethanolamine and diverse amino acids in 
frontocortical dialysates of freely-moving rats: Differential modulation by N-methyl-D-aspartate (NMDA) and other pharmacological agents. J Neurosci Methods 202(2):143-157. https://doi.org/ 10.1016/j.jneumeth.2011.08.040

52. Perio A, Terranova JP, Worms P, Bluthe RM, Dantzer R, Biziere K (1989) Specific modulation of social memory in rats by cholinomimetic and nootropic drugs, by benzodiazepine inverse agonists, but not by psychostimulants. Psychopharmacology 97(2):262-268

53. Nuechterlein KH, Robbins TW, Einat H (2005) Distinguishing separable domains of cognition in human and animal studies: What separations are optimal for targeting interventions? A summary of recommendations from breakout group 2 at the measurement and treatment research to improve cognition in schizophrenia new approaches conference. Schizophr Bull 31(4):870-874. https://doi.org/10.1093/schbul/sbi047

54. Watson DJG, Loiseau F, Ingallinesi M, Millan MJ, Marsden CA, Fone KCF (2012) Selective blockade of dopamine D-3 receptors enhances while D-2 receptor antagonism impairs social novelty discrimination and novel object recognition in rats: A key role for the prefrontal cortex. Neuropsychopharmacology 37(3):770-786. https://doi.org/10.1038/npp.2011.254

55. Loiseau F, Millan MJ (2009) Blockade of dopamine D-3 receptors in frontal cortex, but not in sub-cortical structures, enhances social recognition in rats: Similar actions of D-1 receptor agonists, but not of D-2 antagonists. Eur Neuropsychopharmacol 19(1):23-33. https://doi.org/10.1016/j.euroneuro.2008.07.012

56. King MV, Seeman P, Marsden CA, Fone KCF (2009) Increased dopamine D2(high) receptors in rats reared in social isolation. Synapse 63(6):476-483. https://doi.org/10.1002/syn.20624

57. Watson DJG, Marsden CA, Millan MJ, Fone KCF (2012) Blockade of dopamine D-3 but not D-2 receptors reverses the novel object discrimination impairment produced by postweaning social isolation: Implications for schizophrenia and its treatment. Int J Neuropsychopharmacol 15(4):471-484. https:// doi.org/10.1017/s1461145711000435

58. Ennaceur A, Delacour J (1988) A new one-trial test for neurobiological studies of memory in rats. 1: Behavioral data. Behav Brain Res 31(1):47-59

59. Rajagopal L, Massey BW, Huang M, Oyamada Y, Meltzer HY (2014) The novel object recognition test in rodents in relation to cognitive impairment in schizophrenia. Curr Pharm Design 20(31):5104-5114. https://doi.org/10.2174/ 1381612819666131216114240

60. Sivakumaran MH, Mackenzie AK, Callan IR, Ainge JA, O'Connor AR (2018) The discrimination ratio derived from novel object recognition tasks as a measure of recognition memory sensitivity, not bias. Sci Rep 8(1):11579-11512. https://doi.org/10. 1038/s41598-018-30030-7

61. King MV, Sleight AJ, Woolley ML, Topham IA, Marsden CA, Fone KCF (2004) 5-HT6 receptor antagonists reverse delaydependent deficits in novel object discrimination by enhancing consolidation - an effect sensitive to NMDA receptor antagonism. Neuropharmacology 47(2):195-204

62. Millan MJ, Buccafusco JJ, Loiseau F, Watson DJG, Decamp E, Fone KCF, Thomasson-Perret N, Hill M et al (2010) The dopamine $\mathrm{D}(3)$ receptor antagonist, $\mathrm{S} 33138$, counters cognitive impairment in a range of rodent and primate procedures. Int $\mathrm{J}$ Neuropsychopharmacol 13(8):1035-1051

63. Anagnostaras SG, Maren S, Sage JR, Goodrich S, Fanselow MS (1999) Scopolamine and Pavlovian fear conditioning in rats: Dose-effect analysis. Neuropsychopharmacology 21(6):731-744. https://doi.org/10.1016/S0893-133X(99)00083-4

64. Herbener ES (2009) Impairment in long-term retention of preference conditioning in schizophrenia. Biol Psychiatry 65(12):10861090. https://doi.org/10.1016/j.biopsych.2009.01.020
65. Lonsdorf TB, Richter J (2017) Challenges of fear conditioning research in the age of RDoC. Zeitschrift Fur Psychologie-J Psychol 225(3):189-199. https://doi.org/10.1027/2151-2604/ a000303

66. Woods S, Clarke NN, Layfield R, Fone KC (2012) 5-HT(6) receptor agonists and antagonists enhance learning and memory in a conditioned emotion response paradigm by modulation of cholinergic and glutamatergic mechanisms. Br J Pharmacol 167(2):436449. https://doi.org/10.1111/j.1476-5381.2012.02022.x

67. Depoortere R, Dargazanli G, Estenne-Bouhtou G, Coste A, Lanneau C, Desvignes C, Poncelet M, Heaulme M et al (2005) Neurochemical, electrophysiological and pharmacological profiles of the selective inhibitor of the glycine transporter-I SSR504734, a potential new type of antipsychotic. Neuropsychopharmacology 30(11):1963-1985. https://doi.org/ 10.1038/sj.npp.1300772

68. Voehringer P, Fuertig R, Ferger B (2013) A novel liquid chromatography/tandem mass spectrometry method for the quantification of glycine as biomarker in brain microdialysis and cerebrospinal fluid samples within $5 \mathrm{~min}$. J Chromatogr B Anal Technol Biomed Life Sci 939:92-97. https://doi.org/10.1016/j. jchromb.2013.09.011

69. Nagy K, Marko B, Zsilla G, Matyus P, Pallagi K, Szabo G, Juranyi Z, Barkoczy J et al (2010) Alterations in brain extracellular dopamine and glycine levels following combined administration of the glycine transporter type-1 inhibitor Org-24461 and risperidone. Neurochem Res 35(12):2096-2106. https://doi.org/10.1007/ s11064-010-0241-0

70. Perry KW, Falcone JF, Fell MJ, Ryder JW, Yu H, Love PL, Katner J, Gordon KD et al (2008) Neurochemical and behavioral profiling of the selective GlyT1 inhibitors ALX5407 and LY2365109 indicate a preferential action in caudal vs. cortical brain areas. Neuropharmacology 55(5):743-754. https://doi.org/10.1016/j. neuropharm.2008.06.016

71. Hofmann C, Pizzagalli F, Boetsch C, Alberati D, Ereshefsky L, Jhee S, Patat A, Boutouyrie-Dumont B et al (2016) Effects of the glycine reuptake inhibitors bitopertin and RG7118 on glycine in cerebrospinal fluid: Results of two proofs of mechanism studies in healthy volunteers. Psychopharmacology 233(13):2429-2439. https://doi.org/10.1007/s00213-016-4317-7

72. Martin-Facklam M, Pizzagalli F, Zhou Y, Ostrowitzki S, Raymont V, Brasic JR, Parkar N, Umbricht D et al (2013) Glycine transporter type 1 occupancy by bitopertin: A positron emission tomography study in healthy volunteers. Neuropsychopharmacology 38(3):504-512. https://doi.org/10.1038/npp.2012.212

73. Strzelecki D, Podgorski M, Kaluzynska O, Stefanczyk L, Kotlicka-Antczak M, Gmitrowicz A, Grzelak P (2015) Adding sarcosine to antipsychotic treatment in patients with stable schizophrenia changes the concentrations of neuronal and glial metabolites in the left dorsolateral prefrontal cortex. Int J Mol Sci 16(10): 24475-24489. https://doi.org/10.3390/ijms161024475

74. Javitt DC (2012) Glycine transport inhibitors in the treatment of schizophrenia. Handb Exp Pharmacol 213:367-399

75. Strzelecki D, Szyburska J, Rabe-Jablonska J (2014) Two grams of sarcosine in schizophrenia - is it too much? A potential role of glutamate-serotonin interaction. Neuropsychiatr Dis Treat 10: 263-266. https://doi.org/10.2147/NDT.S54024

76. Bannai M, Kawai N, Nagao K, Nakano S, Matsuzawa D, Shimizu E (2011) Oral administration of glycine increases extracellular serotonin but not dopamine in the prefrontal cortex of rats. Psychiatry Clin Neurosci 65(2):142-149. https://doi.org/10.1111/ j.1440-1819.2010.02181.x

77. Millan MJ, Brocco M, Gobert A, Joly F, Bervoets K, Rivet J, Newman-Tancredi A, Audinot V et al (1999) Contrasting mechanisms of action and sensitivity to antipsychotics of phencyclidine versus amphetamine: Importance of nucleus accumbens 5-HT2A 
sites for PCP-induced locomotion in the rat. Eur J Neurosci 11(12):4419-4432

78. Ishiwata S, Umino A, Nishikawa $\mathrm{T}$ (2018) Involvement of neuronal and glial activities in control of the extracellular d-serine concentrations by the AMPA glutamate receptor in the mouse medial prefrontal cortex. Neurochem Int 119:120-125. https://doi.org/10. 1016/j.neuint.2017.09.009

79. Sason H, Billard JM, Smith GP, Safory H, Neame S, Kaplan E, Rosenberg D, Zubedat S et al (2017) Asc-1 transporter regulation of synaptic activity via the tonic release of d-serine in the forebrain. Cereb Cortex 27(2):1573-1587. https://doi.org/10.1093/ cercor/bhv350

80. Fujihira T, Kanematsu S, Umino A, Yamamoto N, Nishikawa T (2007) Selective increase in the extracellular D-serine contents by D-cycloserine in the rat medial frontal cortex. Neurochem Int 51(2-4):233-236. https://doi.org/10.1016/j.neuint.2007.06.003

81. Horio M, Mori H, Hashimoto K (2013) Is D-cycloserine a prodrug for D-serine in the brain? Biol Psychiatry 73(12):e33-e34. https:// doi.org/10.1016/j.biopsych.2012.07.013

82. Eddins D, Hamill TG, Puri V, Cannon CE, Vivian JA, SanabriaBohorquez SM, Cook JJ, Morrow JA et al (2014) The relationship between glycine transporter 1 occupancy and the effects of the glycine transporter 1 inhibitor RG1678 or ORG25935 on object retrieval performance in scopolamine impaired rhesus monkey. Psychopharmacology 231(3):511-519. https://doi.org/10.1007/ s00213-013-3260-0

83. Liem-Moolenaar M, Zoethout RWM, de Boer P, Schmidt M, de Kam ML, Cohen AF, Franson KL, van Gerven JMA (2010) The effects of the glycine reuptake inhibitor R213129 on the central nervous system and on scopolamine-induced impairments in psychomotor and cognitive function in healthy subjects. J Psychopharmacol 24(11):1671-1679. https://doi.org/10.1177/ 0269881109106942

84. Shimazaki T, Kaku A, Chaki S (2010) D-serine and a glycine transporter-1 inhibitor enhance social memory in rats. Psychopharmacology 209(3):263-270. https://doi.org/10.1007/ s00213-010-1794-y

85. Assini FL, Duzzioni M, Takahashi RN (2009) Object location memory in mice: Pharmacological validation and further evidence of hippocampal CA1 participation. Behav Brain Res 204(1):206211. https://doi.org/10.1016/j.bbr.2009.06.005

86. Ozawa T, Kumeji M, Yamada K, Ichitani Y (2012) D-Cycloserine enhances spatial memory in spontaneous place recognition in rats. Neurosci Lett 509(1):13-16. https://doi.org/10.1016/j.neulet. 2011.12.031

87. Bado P, Madeira C, Vargas-Lopes C, Moulin TC, WasilewskaSampaio AP, Maretti L, de Oliveira RV, Amaral OB et al (2011) Effects of low-dose D-serine on recognition and working memory in mice. Psychopharmacology 218(3):461-470. https://doi.org/10. 1007/s00213-011-2330-4

88. Chaki S, Shimazaki T, Karasawa J, Aoki T, Kaku A, Iijima M, Kambe D, Yamamoto S et al (2015) Efficacy of a glycine transporter 1 inhibitor TASP0315003 in animal models of cognitive dysfunction and negative symptoms of schizophrenia. Psychopharmacology 232(15):2849-2861. https://doi.org/10. 1007/s00213-015-3920-3

89. Karasawa J, Hashimoto K, Chaki S (2008) D-Serine and a glycine transporter inhibitor improve MK-801-induced cognitive deficits in a novel object recognition test in rats. Behav Brain Res 186(1): 78-83. https://doi.org/10.1016/j.bbr.2007.07.033

90. Hashimoto K, Fujita Y, Ishima T, Chaki S, Iyo M (2008) Phencyclidine-induced cognitive deficits in mice are improved by subsequent subchronic administration of the glycine transporter-1 inhibitor NFPS and D-serine. Eur Neuropsychopharmacol 18(6):414-421. https://doi.org/10.1016/ j.euroneuro.2007.07.009
91. Schneider JS, Tinker JP, Van Velson M, Giardiniere M (2000) Effects of the partial glycine agonist D-cycloserine on cognitive functioning in chronic low dose MPTP-treated monkeys. Brain Res 860(1-2):190-194

92. Matsuoka N, Aigner TG (1996) D-cycloserine, a partial agonist at the glycine site coupled to N-methyl-D-aspartate receptors, improves visual recognition memory in rhesus monkeys. J Pharmacol Exp Ther 278(2):891-897

93. Rajagopal L, Burgdorf JS, Moskal JR, Meltzer HY (2016) GLYX13 (rapastinel) ameliorates subchronic phencyclidine- and ketamine-induced declarative memory deficits in mice. Behav Brain Res 299:105-110. https://doi.org/10.1016/j.bbr.2015.10. 060

94. Millan MJ, Agid Y, Brune M, Bullmore ET, Carter CS, Clayton NS, Connor R, Davis S et al (2012) Cognitive dysfunction in psychiatric disorders: Characteristics, causes and the quest for improved therapy. Nat Rev Drug Discov 11(2):141-168. https://doi. org/10.1038/nrd3628

95. Portero-Tresserra M, Cristobal-Narvaez P, Marti-Nicolovius M, Guillazo-Blanch G, Vale-Martinez A (2013) D-cycloserine in prelimbic cortex reverses scopolamine-induced deficits in olfactory memory in rats. PLoS One 8(8):e70584. https://doi.org/10. 1371/journal.pone.0070584

96. DeVito LM, Balu DT, Kanter BR, Lykken C, Basu AC, Coyle JT, Eichenbaum H (2011) Serine racemase deletion disrupts memory for order and alters cortical dendritic morphology. Genes Brain Behav 10(2):210-222. https://doi.org/10.1111/j.1601-183X. 2010.00656.x

97. Fabricius K, Helboe L, Fink-Jensen A, Wortwein G, SteinigerBrach B, Sotty F (2010) Increased dopaminergic activity in socially isolated rats: An electrophysiological study. Neurosci Lett 482(2):117-122. https://doi.org/10.1016/j.neulet.2010.07.014

98. Fabricius K, Helboe L, Fink-Jensen A, Wortwein G, SteinigerBrach B (2010) Pharmacological characterization of social isolation-induced hyperactivity. Psychopharmacology (Berl) 215(2):257-266. https://doi.org/10.1007/s00213-010-2128-9

99. Stromme Johannesen T, Myhrer T (2002) Impaired visual memory in rats reared in isolation is reversed by $\mathrm{D}$-cycloserine in the adult rat. Eur J Pharmacol 437(1-2):73-77

100. Hutson PH, Clark JA, Cross AJ (2017) CNS target identification and validation: Avoiding the valley of death or naive optimism? Annu Rev Pharmacol Toxicol 57:171-187. https://doi.org/10. 1146/annurev-pharmtox-010716-104624

101. Goetghebeur PJ, Swartz JE (2016) True alignment of preclinical and clinical research to enhance success in CNS drug development: A review of the current evidence. J Psychopharmacol 30(7):586-594. https://doi.org/10.1177/0269881116645269

102. Quartermain D, Mower J, Rafferty MF, Herting RL, Lanthorn TH (1994) Acute but not chronic activation of the NMDA-coupled glycine receptor with D-cycloserine facilitates learning and retention. Eur J Pharmacol 257(1-2):7-12

103. Nong Y, Huang YQ, Ju W, Kalia LV, Ahmadian G, Wang YT, Salter MW (2003) Glycine binding primes NMDA receptor internalization. Nature 422(6929):302-307. https://doi.org/10.1038/ nature 01497

104. Buchanan RW, Javitt DC, Marder SR, Schooler NR, Gold JM, McMahon RP, Heresco-Levy U, Carpenter WT (2007) The cognitive and negative symptoms in schizophrenia trial (CONSIST): The efficacy of glutamatergic agents for negative symptoms and cognitive impairments. Am J Psychiatry 164(10):1593-1602. https://doi.org/10.1176/appi.ajp.2007.06081358

105. Shimizu S, Sogabe S, Yanagisako R, Inada A, Yamanaka M, Iha HA, Ohno Y (2017) Glycine-binding site stimulants of NMDA receptors alleviate extrapyramidal motor disorders by activating the nigrostriatal dopaminergic pathway. Int J Mol Sci 18(7). https://doi.org/10.3390/ijms18071416 
106. Lin CH, Lin CH, Chang YC, Huang YJ, Chen PW, Yang HT, Lane HY (2018) Sodium benzoate, a D-amino acid oxidase inhibitor, added to clozapine for the treatment of schizophrenia: A randomized, double-blind, placebo-controlled trial. Biol Psychiatry 84(6): 422-432. https://doi.org/10.1016/j.biopsych.2017.12.006

107. Jacobs KR, Castellano-Gonzalez G, Guillemin GJ, Lovejoy DB (2017) Major developments in the Design of Inhibitors along the Kynurenine pathway. Curr Med Chem 24(23):2471-2495. https:// doi.org/10.2174/0929867324666170502123114

108. Bortz DM, Wu HQ, Schwarcz R, Bruno JP (2017) Oral administration of a specific kynurenic acid synthesis (KAT II) inhibitor attenuates evoked glutamate release in rat prefrontal cortex. Neuropharmacology 121:69-78. https://doi.org/10.1016/j. neuropharm.2017.04.023

109. Ishiwata S, Ogata S, Umino A, Shiraku H, Ohashi Y, Kajii Y, Nishikawa T (2013) Increasing effects of S-methyl-L-cysteine on the extracellular D-serine concentrations in the rat medial frontal cortex. Amino Acids 44(5):1391-1395. https://doi.org/10. 1007/s00726-013-1464-6

110. Brown JM, Hunihan L, Prack MM, Harden DG, Bronson J, Dzierba CD, Gentles RG, Hendricson A et al (2014) In vitro characterization of a small molecule inhibitor of the alanine serine cysteine transporter -1 (SLC7A10). J Neurochem 129(2):275283. https://doi.org/10.1111/jnc.12618

111. Guercio GD, Panizzutti R (2018) Potential and challenges for the clinical use of d-serine as a cognitive enhancer. Front Psychiatry 9: 14. https://doi.org/10.3389/fpsyt.2018.00014

112. Madeira C, Lourenco MV, Vargas-Lopes C, Suemoto CK, Brandao CO, Reis T, Leite RE, Laks J et al (2015) d-serine levels in Alzheimer's disease: Implications for novel biomarker development. Transl Psychiatry 5:e561. https://doi.org/10.1038/tp. 2015.52

113. Billard JM (2013) Serine racemase as a prime target for age-related memory deficits. Eur J Neurosci 37(12):1931-1938. https://doi. org/10.1111/ejn. 12226
114. Lin CH, Yang HT, Chiu CC, Lane HY (2017) Blood levels of Damino acid oxidase vs. D-amino acids in reflecting cognitive aging. Sci Rep 7(1):14849. https://doi.org/10.1038/s41598-01713951-7

115. Modi ME, Young LJ (2011) D-cycloserine facilitates socially reinforced learning in an animal model relevant to autism spectrum disorders. Biol Psychiatry 70(3):298-304. https://doi.org/10.1016/ j.biopsych.2011.01.026

116. Na ES, De Jesus-Cortes H, Martinez-Rivera A, Kabir ZD, Wang J, Ramesh V, Onder Y, Rajadhyaksha AM et al (2017) D-cycloserine improves synaptic transmission in an animal model of Rett syndrome. PLoS One 12(8):e0183026. https://doi.org/10.1371/ journal.pone.0183026

117. Price KL, Baker NL, McRae-Clark AL, Saladin ME, Desantis SM, Santa Ana EJ, Brady KT (2013) A randomized, placebocontrolled laboratory study of the effects of D-cycloserine on craving in cocaine-dependent individuals. Psychopharmacology 226(4):739-746. https://doi.org/10.1007/s00213-011-2592-x

118. Armbruster A, Neumann E, Kotter V, Hermanns H, Werdehausen R, Eulenburg V (2017) The GlyT1 inhibitor bitopertin ameliorates allodynia and hyperalgesia in animal models of neuropathic and inflammatory pain. Front Mol Neurosci 10:438. https://doi.org/10. 3389/fnmol.2017.00438

119. Otto MW, Kredlow MA, Smits JAJ, Hofmann SG, Tolin DF, de Kleine RA, van Minnen A, Evins AE et al (2016) Enhancement of psychosocial treatment with D-cycloserine: Models, moderators, and future directions. Biol Psychiatry 80(4):274-283. https://doi. org/10.1016/j.biopsych.2015.09.007

Publisher's Note Springer Nature remains neutral with regard to jurisdictional claims in published maps and institutional affiliations. 